IZA DP No. 10040

Do Parents Tax Their Children?

Teenage Labour Supply and Financial Support

Angus Holford

July 2016 


\title{
Do Parents Tax Their Children? Teenage Labour Supply and Financial Support
}

\author{
Angus Holford \\ ISER, University of Essex \\ and IZA
}

Discussion Paper No. 10040

July 2016

IZA

P.O. Box 7240

53072 Bonn

Germany

Phone: +49-228-3894-0

Fax: +49-228-3894-180

E-mail: iza@iza.org

Any opinions expressed here are those of the author(s) and not those of IZA. Research published in this series may include views on policy, but the institute itself takes no institutional policy positions. The IZA research network is committed to the IZA Guiding Principles of Research Integrity.

The Institute for the Study of Labor (IZA) in Bonn is a local and virtual international research center and a place of communication between science, politics and business. IZA is an independent nonprofit organization supported by Deutsche Post Foundation. The center is associated with the University of Bonn and offers a stimulating research environment through its international network, workshops and conferences, data service, project support, research visits and doctoral program. IZA engages in (i) original and internationally competitive research in all fields of labor economics, (ii) development of policy concepts, and (iii) dissemination of research results and concepts to the interested public.

IZA Discussion Papers often represent preliminary work and are circulated to encourage discussion. Citation of such a paper should account for its provisional character. A revised version may be available directly from the author. 


\section{ABSTRACT \\ Do Parents Tax Their Children? Teenage Labour Supply and Financial Support ${ }^{\star}$}

This paper models child employment and parental pocket money decisions as a noncooperative game. Assuming that the child human capital is a household public good and that the relationship between child human capital and employment is concave, we compare the welfare obtained under different decision-making mechanisms and test the predictions of the model for a cohort of English teenagers in compulsory education. Our results support a situation in which parents 'tax' their children's earnings, withdrawing financial support as the child increases his working hours. This strategy forces the child to internalise the social cost of his activities.

\section{JEL Classification: $\quad$ C52, C72, D13, J22}

Keywords: intra-household transfers, pocket money, child labour supply, noncooperative game, human capital

Corresponding author:

Angus Holford

Institute for Social and Economic Research

University of Essex

Wivenhoe Park

Colchester, CO4 3SQ

United Kingdom

E-mail: ajholf@essex.ac.uk

\footnotetext{
* This work was carried out during PhD studies supported by an Economic and Social Research Council '1+3' studentship in Economics [reference number ES/I025499/1], and postdoctoral research supported by the Economic and Social Research Council Research Centre on Micro-Social Change [reference number ES/L009153/1]. Thanks in particular for advice from supervisors and colleagues Emilia Del Bono, Stephen Pudney and Matthias Parey, and my PhD examiners Pedro Carneiro and Thomas Crossley, as well as seminar participants at Essex, the Family Economics Workshop at Royal Holloway, and the IZA Summer School in Labour Economics. All errors are my own. This work is based on data from the Longitudinal Study of Young People in England (Secure Data Service Access), produced by the Department for Education and National Centre for Social Research, and supplied through the Secure Data Service at the UK Data Archive. This work also uses local labour market statistics produced by the Office for National Statistics. The data are crown copyright and reproduced with the permission of the controller of the HMSO and Queens's Printer for Scotland. The use of the data in this work does not imply the endorsement of the Department for Education, National Centre for Social Research, ONS, or Secure Data Service at the UK Data Archive in relation to the interpretation or analysis of these data.
} 


\section{NON-TECHNICAL SUMMARY}

Young adults who are still living with their parents and still in compulsory education finance their independent consumption using either parental transfers (pocket money), or by working part-time. Parents care about their own and their children's consumption, but also about the effect that part-time work might have on their children's study time and academic achievement, so are prepared to sacrifice some of their income to subsidize their children's expenses. This paper investigates how parents and their teenage children interact to set the amounts of (i) pocket money and (ii) part-time work.

We use data on part-time working hours, and pocket money from parents, reported by around 5000 girls and 5000 boys in compulsory education in England, interviewed annually between 2004 (when they were 14) and 2006 (when they were 16). At age 14, 25\% of boys but only $19 \%$ of girls had a part-time job. By age 16, girls had overtaken (32\% against 29\%) but were earning slightly lower wages for similar hours ( $£ 4.06$ against $£ 4.34$ per hour, both for about 6.5 hours a week). The propensity to offer regular allowances from parents was very similar for boys and girls, at around $80 \%$ over this period.

Children take into account the money they get from parents when deciding whether to work or not. At age 14 they are 10-15 percentage points less likely to work if they are receiving an allowance, and this gap increases to 20 percentage points by age 16 . Similarly, parents are around 15 percentage points less likely to give an allowance if their child is in paid work.

Our empirical analysis of parents' and children's behaviour reveals two key findings. The first is that, other things equal, parents are more likely to give regular pocket money to teenagers who will have a harder time finding a job. This includes teenagers who are younger within their academic year at school so at a disadvantage when vacancies arise in the autumn, both before the run-up to Christmas and when older cohorts leave for university; those living in areas with higher rates of adult unemployment; and those living in areas from which the nearest shops are less accessible. This tells us that rather than being opportunistic ("these parents don't need to pay their children not to work, so they don't"), parents effectively 'insure' their child's independent consumption against labour market difficulties outside their control. They would like them to finance their own personal spending money, but will not penalize them if this proves difficult.

The second is that parents are less likely give regular pocket money to teenagers, the longer the teenager's hours of part-time work. In other words, parents effectively tax their children's earnings from part-time work, by taking away cash they would otherwise be handing over. This effect is larger for girls than boys and strongest when they are 16 years-old. We suggest that close to the high-stakes GCSE exams, which determine these children's future educational and labour market opportunities, parents become more inclined to use their financial resources to reduce their child's incentive to work, hoping they will spend more time studying instead. 


\section{Introduction}

As teenagers become older they increasingly demand independence over their consumption and time use (Dauphin et al., 2011). However, while remaining in compulsory education they are dependent on in-kind or financial transfers from parents to support their living expenses. They may also undertake part-time work in the labour market. Many do. The data used here shows that around 25\% of 13-16 year-olds below the minimum school leaving age in England have a job during school term time. In the US, employment rates are considerably higher: approximately $60 \%$ for 14-15 year-olds (Buscha et al., 2008, Bureau of Labor Statistics, 2000), with 92\% of the National Longitudinal Study of Youth (NLSY) 1997 cohort having worked at some point during High School (Hotz et al., 2002).

Having a job while still at school may improve teenagers' welfare by affording them additional independent consumption, and potentially improves their stock of human capital in the form of financial literacy, communication skills and lower discount rates (Oettinger, 1999; Light, 2001). Conversely, by crowding out time and effort devoted to education, in-school employment may impair the child's academic performance and subsequent educational or labour market opportunities (Ruhm, 1997, Department for Children, Schools and Families, 2009). Above a moderate number of hours per week the latter effect has been shown to dominate. This critical threshold also becomes lower, the closer to exam time (Lillydahl, 1990; Payne, 2004).

Being unable to earn a living wage, teenagers in full-time compulsory education have no 'outside option' or bargaining power within the household (McElroy and Horney, 1981; Browning and Chiappori, 1998). In this environment, it is convenient to abstract from the child's actions and preferences when modelling the household's decision-making processes. Several studies either implicitly invoke Becker's $(1974,1981)$ 'rotten kid theorem', assuming the existence of an altruistic head-of-household who is able to transfer resources among household members and so (under certain conditions - Bergstrom, 1989; Ermisch, 2003) automatically induce the child to maximise household utility (Bingley and Walker, 2013), or treat children as goods rather than agents (Bourguignon, 1999; Blundell et al., 2005). When teenagers are able to take part-time employment these characterisations are less easily supported. The child's labour market activity increases the household's full income, but also either contributes to or reduces the child's level of human capital, which in the presence of an altruistic parent can be treated as a household public good. This situation is similar to the time allocation decision faced by a couple over labour 
supply and household production, wherein the free rider problem leads to underprovision of the public good (Konrad and Lommerud, 1995). Assuming the parent has a lower discount rate than the child (Burton et al., 2002), making her paternalistic or impurely altrustic, she will weight the child's human capital more heavily relative to the child's consumption than will the child himself. The child's labour market activity therefore creates an externality: the 'rotten kid theorem' does not apply because in the absence of a specific mechanism design the child will work too many hours and produce too little human capital, relative to the (parent's) social optimum.

In this paper we identify the decision-making process governing parent-child interactions in respect of the child's part-time labour supply. We consider three ways in which parents can use their financial resources to alter their child's incentive to get a job. They can set a fixed transfer level taking the child's decision as given (a Nash equilibrium), or announce their transfer in advance of the child's decision (a parent-leading Stackelberg model), or withdraw transfers in response to the child's employment (a child-leading Stackelberg model).

The former two models assume that children take their parents' transfer level as given when making their labour supply choice. This is the most common assumption so far adopted in the literature. Dustmann et al. (2009), using data on UK 14-15 year-olds in 1974, show children's labour supply is highly responsive to parental transfers, with an income elasticity similar to that of adults. Gong (2009) (with data on US 12-16 year-olds in 1997) and Kalenkoski and Pabilonia (2010) (US college students between 1997 and 2003) found a significant but more modest elasticity. Wolff (2006), analysed French young adults aged 16-22 in 1992 and found no effect. As well as providing new evidence for a recent UK cohort (14-16 year olds in 2004-2006), we extend this literature by explicitly considering the implications of an impurely altruistic parent who cares relatively more about the child's human capital, and by exploring the implications of the child-leading Stackelberg model, in which parents set a contingent transfer schedule, as a potential alternative decision making process. This model implies that parents effectively tax their child's earnings.

As noted by Kooreman and Kapteyn (1990), a problem for applied work on household labour supply is that it is not clear which theoretical model to implement empirically, and Apps and Rees (1996) show that estimating misspecified models of intra-household income and labour supply interactions can result in highly misleading inference. We address this key identification 
problem by inferring the decision-making process used by households in two stages. First we analyse the welfare implications of each model in a theoretical framework, then we take testable predictions from each model to the data. This approach contrasts with other work in which the decision-making process for parent-child interactions has been elicited directly (Lundberg et al., 2009), which carries the potential for responses to to be driven by social desirability (Conti and Pudney, 2011) or for households' arrangements to be tacit rather than explicit, making answers unreliable.

In our first step we show that with an impurely altruistic parent the Nash equilibrium is Paretodominated, and so should be rejected on welfare grounds: both the parent and the child will always be better off at a Stackelberg equilibrium. However, the parent-leading and the childleading Stackelberg models are non-nested and neither is a priori welfare-superior, so we then test predictions derived from these models using data from the Longitudinal Study of Young People in England (LSYPE). The parent leading Stackelberg would predict that parents are opportunistic in terms of reducing financial transfers in response to factors restricting the child's work opportunities, but we instead show that parents insure their child's consumption against labour market difficulties outside their control (Ermisch, 2003, p.5). Our results are consistent with a decision-making process in which parents 'tax' their children's earnings, withdrawing financial support as child labour supply increases. This is in line with the predictions of the child-leading Stackelberg model.

While there is strong evidence about the primacy of the role of parents in promoting financial literacy and financial socialization of young adults, outweighing the contributions from part-time work or from formal education (Shim et al., 2010), giving pocket money alone (characteristic of the Nash and parent-leading Stackelberg models) is shown to be ineffective for stimulating adult savings (Bucciol and Veronesi, 2014). Our finding shows that parents combine their giving of pocket money with communication about a trade-off teenagers face when making an important financial decision, which is an encouraging model for promoting the the financial literacy of young adults.

We make an additional contribution to the empirical literature by repeating our analysis on the same cross-section of parents and children in successive years. This enables us to evaluate how the parameters of the model change as teenagers get older, while holding constant the other factors (country, education level, era) collectively driving the differences between the labour 
supply and transfer elasticities seen in the earlier literature. In particular, we show a significant increase in the propensity of parents to 'tax' the part-time earnings of girls during their final year of compulsory schooling when high stakes GCSE examinations are taken over earlier years. This is consistent with parents using their financial resources to discourage part-time work, during the periods when the opportunity cost of part-time work is highest.

\section{Theoretical Model}

Our model assumes two agents, a selfish child and an altruistic parent. The child cares about his own consumption $(C)$ and his own human capital $(H)$. The parent cares about her own consumption $(P)$, the child's consumption, and the child's human capital. The utility functions depend on each agent's relative preference for child's human capital over child's consumption, denoted $\kappa_{c}$ (child) and $\kappa_{p}$ (parent). Here we assume that the parent's altruism is impure or paternalistic, meaning that $\kappa_{p}>\kappa_{c}$. Each agent's $\kappa$ is a predetermined function of exogenous individual and household preferences and characteristics, $\mathbf{X}$, so $\kappa_{i}=\kappa_{i}(\mathbf{X})$ for $i=p, c$. The utility functions can be written $U^{c}=U^{c}\left(C, H, \kappa_{c}(\mathbf{X})\right)$ (child) and $U^{p}=U^{p}\left(C, P, H, \kappa_{p}(\mathbf{X})\right)$ (parent). Both are three times continuously differentiable in $C, P$ and $H$; strictly increasing in $C, P$ and $H$ at a dimishing rate; and separable in $C, P$ and $H$, such that the marginal utility from each element is independent of the other elements. ${ }^{1}$

Prior to making his labour supply decision, the child has a baseline endowment of human capital, $\mu$. This is also a predetermined function of $\mathbf{X}$, so $\mu=\mu(\mathbf{X})$. These current and past parental, child and household characteristics are assumed to have determined the parent and child's time and effort devoted to investment activities over the preceding lifecourse. The child's human capital accumulation in a given period is also a function of his time devoted to wage-earning employment $L$, so $H=H(L, \mu)$. We assume that the marginal human capital product $\left(H_{L}\right)$ of the first hour of labour supply can be positive or negative, but $\left(H_{L}\right)$ is decreasing in $L$ (so $H_{L L}<0$ ). This captures the idea that beyond some level of hours of work employment must detract from the quality or quantity of time devoted to other human-capital earning pursuits. This is consistent with the findings of Ruhm (1997), Tyler (2003) and Montmarquette et al. (2007), among others, and we assume that this stylised fact is built into individuals'

\footnotetext{
${ }^{1}$ Formally, the restrictions on the child's utility function are: $U_{C}^{c}>0 ; U_{C C}^{c}<0 ; U_{H}^{c}>0 ; U_{H H}^{c}<0 ; U_{C H}^{c}=0$. The restrictions on the parent's utility function are: $U_{C}^{p}>0 ; U_{C C}^{p}<0 ; U_{P}^{p}>0 ; U_{P P}^{p}<0 ; U_{H}^{p}>0 ; U_{H H}^{p}<0$; $U_{P H}^{p}=0 ; U_{P C}^{p}=0 ; U_{H C}^{p}=0$.
} 
expectations.

In our model, the parent has exogenous income $M$, and can choose to transfer the cash amount $t \geq 0$ to the child. The parent consumes the rest of her income, so $P=M-t$. The child chooses his labour supply, $L$, and earns the constant wage $w>0$. His consumption is the sum of labour earnings $w L$, and money received from parents: $C=w L+t$.

Observed transfer and labour supply behaviour represents the solution to the one-shot game in which the parent and child each maximise their own utility in the current period subject to their preferences and production function of human capital.

We assume that parents and children do not have a mechanism for a complete, binding commitment. This means we adopt a non-cooperative model. This is supported by empirical evidence showing there is imperfect communication between the parent and child during adolescence, a period in which young people establish their identity and develop the ability to make their own decisions (Collins, 1990). As Lundberg et al. (2009) put it, "effective information exchange [is] hampered by the [child's] still-developing cognitive and communicative abilities". These communication difficulties stem from both the asymmetric relationship between parents and adolescents and divergent expectations about the child's autonomy (Steinberg, 2001; Collins and Luebker, 1994), and from the changing nature of the relationship over time (Collins et al, 1997), leading to an unstable bargaining environment ("constantly changing as the child matures"; Lundberg et al., 2009).

In our theoretical model, we follow Burton et al. (2002) and Schmidt (1993) by assuming that the parent has developed a reputation and the child's discount rate is sufficiently high that he takes the parent's strategy (though not necessarily action) as given in each period. We then build on two subsequent approaches to modelling household labour supply adopted in the earlier literature (see Apps and Rees, 2009, pp.75-76, for a discussion). Firstly we model the child's consumption and human capital as a household public good, and secondly we derive and identify best response functions for both agents' decision variables (Antman, 2012; Leuthold, 1968; Ashworth and Ulph, 1981).

In the following sections will derive the unique equilibrium under (i) the Nash decision-making process, (ii) the parent-leading Stackelberg model, and (iii) child-leading Stackelberg model. This final model can also be framed as the parent setting a contingent transfer schedule. 


\subsection{Nash and Stackelberg equilibria}

In a Nash framework, the parent and child choose their cash transfer and labour supply as their best response to the other's action. At the Nash equilibrium, neither agent can do better, taking the other's action as given. Implicitly, this position is reached by a myopic adjustment procedure or iterative process in which the agents choose starting positions and best-respond in turn to converge on the equilibrium (Leonard, 1994). In the Stackelberg framework, one party 'leads' by committing to the action that maximises their own utility taking into account that the other agent will 'best respond' to the leader's actions. Here, there are two Stackelberg equilibria, one in which the parent leads and one in which the child leads.

In the parent-leading Stackelberg model, the parent fixes the cash transfer in advance. The child follows with his best response in terms of employment, taking the cash transfer as given. We assume the parent can costlessly and rapidly alter the transfers. However, this flexibility threatens the parent's credibility or time-consistency. A Stackelberg equilibrium requires the follower to believe the leader will not deviate from her initial action. In an application of the 'Samaritan's Dilemma' (Bruce and Waldman, 1991; Lindbeck and Weibull, 1988) this means that the parent must hold the transfer level fixed in case of the child being involuntarily unemployed or under-employed, and that parental transfers do not respond to changes in labour market conditions.

In the child-leading Stackelberg model, the child anticipates the parent's best response and 'leads' by choosing his employment level. The parent then follows with his best response in terms of cash transfers, taking the employment level as given. We assume the parent has deterministic control over cash transfers. This means the child's first-move commitment will not come under challenge due to the parent deviating from her expected best-response for reasons outside her control. The child's labour supply decision is less reversible than the parent's transfer decision. The child can leave a job but not easily find another job or adjust his hours. These considerations mean the employment level is more likely to represent a credible, binding commitment than the transfer level.

The parent's relative financial resources, lower discount rate, and position of authority within the household, and the child's lack of an outside option should all mean the parent has all of the bargaining power (McElroy and Horney, 1981; Browning and Chiappori, 1998). The idea of a child-leading Stackelberg model, in which the parent 'does the best she can given the action of 
a dominant child' is therefore not intuitively appealing. However, this scenario can be reframed as the parent announcing a contingent schedule of transfers that will be made for every possible level of employment the child can take, and the child choosing the point along it which is best for him. Note that with a fully contingent strategy, there is no time-consistency problem for the parent.

Hence, both the parent-leading and child-leading Stackelberg models are consistent with a situation in which the parent has the bargaining power and chooses the decision-making process. We assume she chooses that which her best off (Bell et al., 2012). We now evaluate the welfare outcomes of the three possible models.

\subsection{Comparing the outcomes of alternative models}

Each agents' optimisation problem can be illustrated graphically in a utility map in the [transfer, labour supply] space, as shown in Figure 1.

Here, the child has a 'bliss point' (point of maximum utility) at infinite transfers and the human capital maximising level of labour supply. The child's best response correspondence, $B R^{c}=L^{*}(t, w, \mathbf{X})$, is the locus of points maximising the child's utility for each given transfer level. This passes through the turning point of each indifference curve $\left(U_{1}^{c}, U_{2}^{c}\right.$, etc). Above the $B R^{c}$, the indifference curve is upward sloping: the marginal human capital cost of working is so high that he requires additional transfers from the parent as well as his own earnings to compensate for it.

As the parent cares relatively more about human capital than does the child, the parent's 'bliss point' lies below the child's best-response correspondence. If the parent is very selfish, the high cost in terms of her own consumption of increasing the child's human capital and consumption will result in a bliss point below the human-capital maximising level of labour supply. The parent's best response correspondence $B R^{p}=t^{*}(L, M, \mathbf{X})$ is the locus of points maximising the parent's utility for each given labour supply. This passes through the maximum and minimum

points of her concentric indifference curves $\left(U_{1}^{p}, U_{2}^{p}\right.$, etc). These carry decreasing utility coming from suboptimal consumption allocations when increasing or decreasing transfers either side of the bliss point, and reduced human capital when increasing labour supply above, or reducing below, the human capital maximising level.

Although next we will set out each agents' optimality conditions and the resulting welfare 
Figure 1: Agents' optimisation problem and the three equilibria

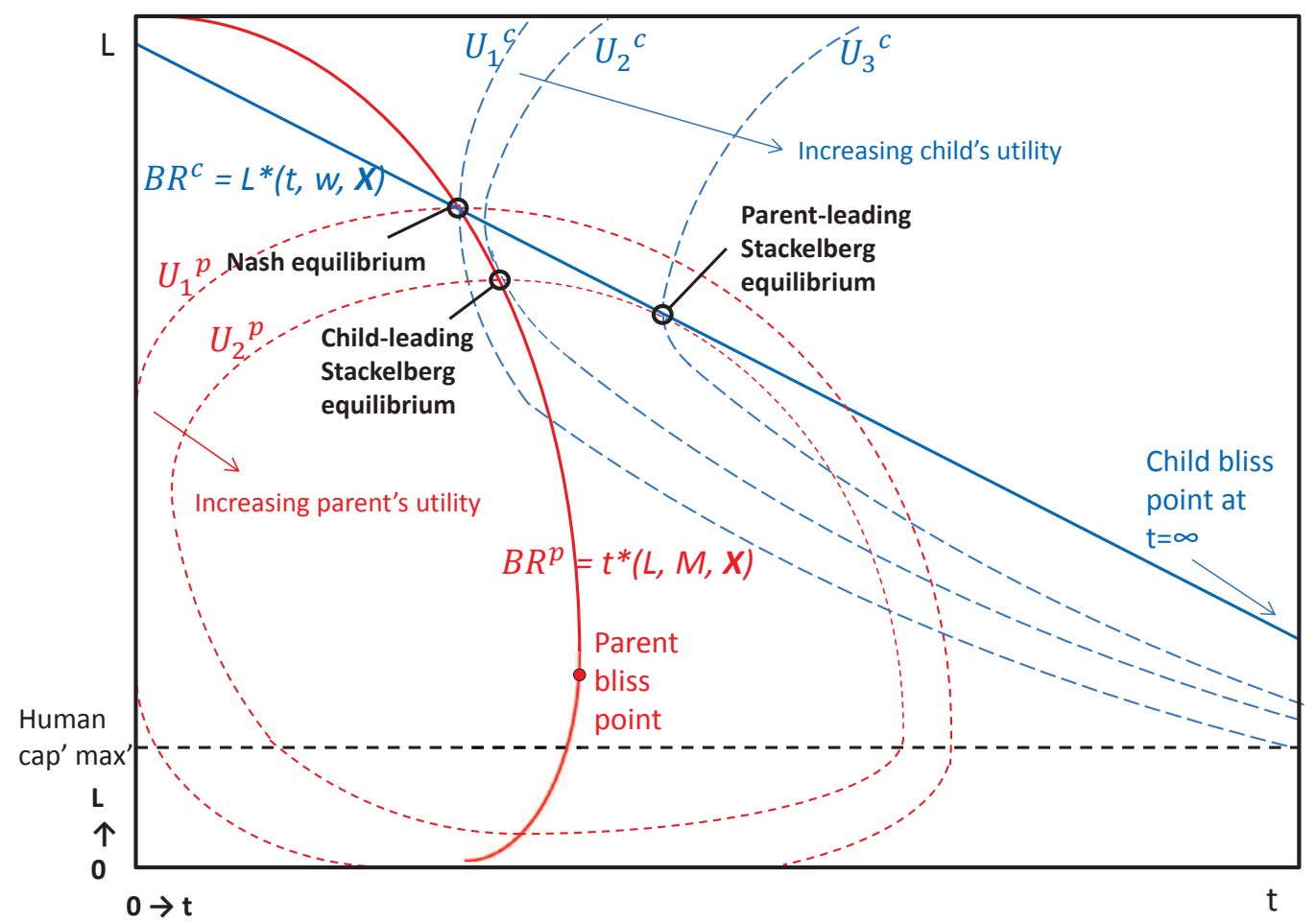

comparisons formally, this utility map shows the intuition for a straightforward interior solution case. The Nash equilibrium, or mutual best response, is at the intersection of the agents' bestresponse correspondences. Both Stackelberg equilibria entail the leader choosing the point on the follower's BR correspondence which makes him or her best off. ${ }^{2}$

\subsubsection{Nash versus parent-leading Stackelberg}

The parent's maximisation problem is the same under a Nash equilibrium as when she acts as a Stackelberg follower. In either case, when choosing her transfer level she takes the child's labour supply $L$ as given:

$$
\max _{t} U^{p}=U^{p}\left(P(M-t), C(w L+t), H\left(L, \mu(\mathbf{X}), \kappa_{p}(\mathbf{X})\right)\right.
$$

${ }^{2}$ Figure 1 shows an interior solution. Because transfers must be non-negative, if at $t=0$ the parent's marginal utility from her own consumption exceeds that from the child's human capital and consumption, she will make zero transfers. If the human capital maximising level of labour supply is $L=0$ and for the first hour of employment the child's marginal utility lost from human capital is greater than that gained from increased consumption, the child will work zero hours. 
and her optimality condition is:

$$
U_{C}^{p}=U_{P}^{p}
$$

This states that the parent will make transfers to the point where her marginal utility from (i) her own consumption, and (ii) the child's consumption and human capital, are equal. This will occur at a maximum or minimum point of a parental indifference curve.

Acting as a Stackelberg leader, the parent's maximisation problem must account for the indirect effects of $t$ on her utility from the child's consumption and human capital, caused by the child's labour supply response to $t$ :

$$
\max _{t} U^{p}=U^{p}\left(P(M-t), C\left(w L^{*}(t)+t\right), H\left(L^{*}(t), \mu(\mathbf{X})\right), \kappa_{p}(\mathbf{X})\right)
$$

Her optimality condition is now:

$$
U_{C}^{p}+\frac{\partial L^{*}}{\partial t}\left[U_{C}^{p} \cdot w+U_{H}^{p} \cdot H_{L}\right]=U_{P}^{p}
$$

She still makes transfers to the point where the marginal utilities from her own consumption and the child's consumption and human capital are equal, but this time accounting for the child's optimal labour supply response. This means she chooses the point on the child's BR correspondence that is tangent to a parental indifference curve. This will represent the parent's highest attainable utility under this framework.

The expression in square brackets in equation (4) is similar to the child's Stackelberg-leading optimality condition (equation 9, below): $w \cdot U_{C}^{c}=-H_{L} \cdot U_{H}^{c}$, or equivalently $w \cdot U_{C}^{c}+H_{L} \cdot U_{H}^{c}=0$. Both expressions are equal to the net change in the parent's utility caused by simultaneous changes in the child's consumption and human capital. If the parent were purely altruistic, placing the same relative weight on the child's human capital and consumption as does the child, then $\left[U_{C}^{p} \cdot w+U_{H}^{p} \cdot H_{L}\right]$ and $\left[U_{C}^{c} \cdot w+U_{H}^{c} \cdot H_{L}\right]$ would both equal zero at the same level of labour supply and transfers. This would mean the parents' bliss point lies on the child's BR, and the Nash and parent-leading Stackelberg equilibria would coincide, as shown by Dustmann et al. (2009). As we assume that the parent's altruism is paternalistic however, at the Nash 
level of transfers it holds that $U_{C}^{p} \cdot w+U_{H}^{p} \cdot H_{L}<0$, and hence:

$$
U_{C}^{p}+\frac{\partial L^{*}}{\partial t}\left[U_{C}^{p} \cdot w+U_{H}^{p} \cdot H_{L}\right]>U_{P}^{p}
$$

From this position, in the Stackelberg model, the parent's paternalism makes her prepared to pay the child more (increase $t$ ) to persuade him to work less (reduce $L$ ). ${ }^{3}$ It can be shown that the child's BR is sufficiently shallow for him always to withdraw labour earnings at a slower rate than transfers are received (see Appendix A.3.1, page 53, for the complete derivation) and both equilibria must lie in the range where the marginal human capital product of labour is negative $\left(H_{L}<0\right)$. Otherwise, the child and parent would always prefer to increase labour supply at the benefit to both human capital and consumption. Hence, both the child's consumption and human capital must be higher at the parent-leading Stackelberg equilibrium than at the Nash equilibrium. Moving from the Nash to the parent-leading Stackelberg equilibrium makes both the parent and the child better off.

\subsubsection{Nash versus child-leading Stackelberg}

The child's maximisation problem when choosing his labour supply is the same under a Nash equilibrium as when he acts as a Stackelberg follower. In both cases, he takes the transfer, $t$, made by the parent, as given:

$$
\max _{L} U^{c}=U^{c}\left(C(w L+t), H(L, \mu(\mathbf{X})), \kappa_{c}(\mathbf{X})\right)
$$

and his optimality condition is:

$$
w \cdot U_{C}^{c}=-H_{L} \cdot U_{H}^{c}
$$

meaning his marginal utility from additional consumption (his gross wage) is equal to that from foregone human capital.

Acting as a Stackelberg leader the child's optimisation problem is as follows:

$$
\max _{L} U^{c}=U^{c}\left(C\left(w L+t^{*}(L)\right), H(L), \mu(\mathbf{X}), \kappa_{c}(\mathbf{X})\right)
$$

\footnotetext{
${ }^{3}$ In Appendix A.1 (page 44) we consider the implications of a parent with a different kind of impure altruistic preferences: those who derive no utility from the child's human capital.
} 
and his optimality condition is:

$$
\left(w+\frac{\partial t^{*}}{\partial L}\right) \cdot U_{C}^{c}=-H_{L} \cdot U_{H}^{c}
$$

The parent withdraws transfers in response to increasing labour supply, so $\frac{\partial t^{*}}{\partial L}<0$, meaning that when acting as a Stackelberg leader, the child instead bases his labour supply on his net wage $\left(w+\frac{\partial t^{*}}{\partial L}\right)$ rather than gross wage. He selects the point on his parents' best response correspondence, which he can view as a contingent tax or transfer schedule, which gives him highest utility. This will occur at a tangent point to a child indifference curve. Formally, at the Nash level of labour supply it holds that:

$$
\left(w+\frac{\partial t^{*}}{\partial L}\right) \cdot U_{C}^{c}<-H_{L} \cdot U_{H}^{c}
$$

At this position, the net wage is too small to compensate the child for the marginal human capital cost of employment. He will therefore reduce his labour supply, raising his human capital and reducing consumption, but become better off overall.

At equilibrium, the 'tax rate' - the slope of the best-response correspondence along which cash transfers from parents are observed to be withdrawn in response to the child's earnings - is strictly between zero and one (see Appendix A.3.2, page 54, for the complete derivation). Above the human capital maximising labour supply, the child will never work for a negative or zero net wage, and the equilibrium cannot occur at a point where the parent is subsidizing the child's employment. The parent only does this where (i) the child's human capital is still increasing in labour supply or (ii) where she would prefer to increase the child's consumption at the cost of reducing her own consumption and her child's human capital. The parent's 'bliss point' will occur at the point where the parent is indifferent between increasing the child's consumption, reducing the child's human capital, and reducing her own consumption. In this state she will neither tax nor subsidise the child's employment. Hence, the child-leading Stackelberg equilibrium must lie at a point on the parent's best-response correspondence between the Nash equilibrium and the parent's bliss point. This means that both the child and the parent are better off at the child-leading Stackelberg equilibrium than the Nash equilibrium. ${ }^{4}$

\footnotetext{
${ }^{4}$ It is a sufficient condition for this welfare improvement that the parent's preferences are paternalistic. One may also consider that if the child-leading Stackelberg equilibrium lay below the parent's bliss point, it would imply that while the child is happy with the trade-off between human capital and consumption, the parent would prefer to raise the child's consumption and reduce his human capital. This would violate our assumption that
} 


\subsection{The identification problem}

If the chosen decision-making process were known, the strategy for identifying each agent's BR correspondence can easily be visualised in Figure 1. In the Nash framework, each agent's BR correspondence is traced out by shifts in the other's BR correspondence, caused by factors having no direct effect on their own. In each Stackelberg model, shifts in the leader's utility map caused by factors having no direct effect on the follower's BR will trace out this BR as the locus of points which are tangent to the leader's highest attainable indifference curve.

However, the chosen decision-making process is ex ante unknown, and estimating misspecified models of intra-household income and labour supply interactions has been shown to result in highly misleading inference (Apps and Rees, 1996). Following Apps and Rees' approach, our identification problem can be illustrated by considering the result we would obtain were we to proceed under the belief that the Nash framework was the correct specification for household behaviour when the true data generating process the is parent-leading Stackelberg model. Then, shifting the child's BR correspondence will trace out a locus of points which are tangent to the parent's indifference curves. This will incorrectly be interpreted as representing the parent's BR correspondence. The case shown in Figure 2 would lead us to conclude that at the equilibrium margin parents are choosing to subsidise, rather than tax, their child's earnings.

To identify the decision-making process we follow first a theoretical and then an empirical argument. We can rule out the observed outcomes ever representing the Nash equilibrium on welfare grounds. We showed in section 2.2, and it is apparent in Figure 1, that both the parent and the child are better off at both the parent-leading and the child-leading Stackelberg equilibria, meaning the Nash equilibrium is Pareto dominated. The parent-leading model is superior even for the child because the parent's paternalism makes him prepared to pay the child more to work less. The child-leading model is superior even for the parent because the positive marginal tax rate faced by the child means he internalises the social cost (in terms of human capital) of his employment. This makes him reduce his labour supply, which pleases the parent.

We assume the parent chooses the decision-making process which gives her the highest utility. Our theoretical framework cannot indicate whether this will be the parent-leading or childleading Stackelberg model. Figure 1 is drawn assuming that the parent is indifferent between the parent cares relatively more about human capital than does the child. 
Figure 2: Erroneous identification of the parent's best response.

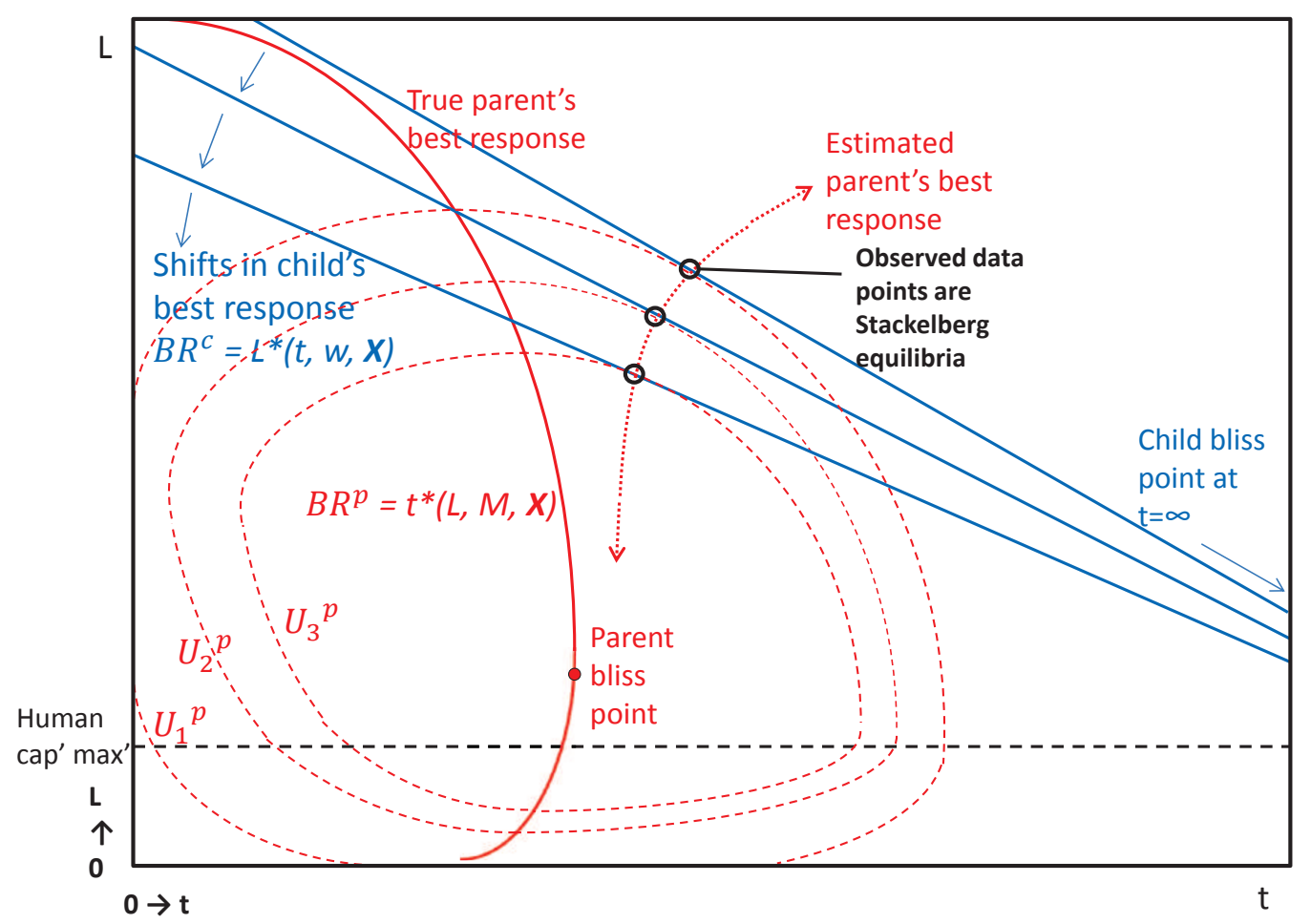

these decision-making processes, receiving utility level $U_{2}^{P}$ in both cases. The more paternalistic are the parent's preferences (characterised by a steeper subsidy and tax on employment below and above the parent's bliss point respectively), the greater scope there is to favour the child-leading model. ${ }^{5}$ The more selfish is the parent overall (characteristed by shifting her BR correspondence to the left and her bliss point to a lower level of labour supply, and reducing the tax and subsidy rates over the relevant ranges), the more scope there is to favour the parent-leading model.

Since we cannot reject either Stackelberg model on theoretical grounds, we must do so on empirical grounds. We now discuss testable predictions derived from the parent-leading Stackelberg model that allow us to validate or reject this model.

\subsection{Labour market rationing and the Stackelberg model}

The parent-leading Stackelberg model requires that the parent will hold transfers constant in response to factors expected to restrict the child's optimal choice (his labour supply or

\footnotetext{
${ }^{5}$ In Appendix A.1 we derive the predictions of the model for the extreme case in which the parent gains no utility from the child's human capital. In this case, we show that the parent-leading model is strictly preferred to the Nash, in turn strictly preferred to the child-leading model.
} 
probability of obtaining a job). Labour demand conditions should have no effect on the agents' preferences or utility except via the child's labour supply. Therefore, a time-consistent parent should ignore these factors in setting his transfer decision.

In addition, if a binding ceiling is placed on the child's hours of employment, then the parent should reduce the transfers made to the child: she no longer needs to "pay the child not to work' and at this ceiling can reduce transfers without trading her rise in consumption against a reduction in the child's human capital. Such a ceiling may result from legal restrictions on the number and timing of hours of employment a child may offer, or from labour demand constraints.

If the parent-leading Stackelberg model is true, therefore, we should find that the effect of the labour demand variables expected to restrict the child's employment opportunities on the transfer are either zero or negative. If this prediction is rejected empirically, the only decisionmaking process left standing is the child-leading Stackelberg model, and we present results which are fully consistent with this framework being used.

\section{$3 \quad$ Data and institutional background}

\subsection{LSYPE data}

We test the predictions of our model using data from the first three waves of the Longitudinal Study of Young People in England (LSYPE). This sample is drawn from a single academic cohort of teenagers in England, interviewed annually from 2004-2006 at age 14 (school year 9), 15 (year 10), and 16 (year 11), the last three years of compulsory schooling. The data enable us to control for a rich set of individual and household variables and the child's prior educational performance.

The question on parental cash transfers is "Do you receive any pocket money, allowances, or other support towards your living costs from parents or relatives?". The emphasis on "allowances" or "support towards your living costs" but without reference to specific items means that this does not refer to hypothecated transfers. The present tense makes clear that this unearned income refers to a current, ongoing, and regular arrangement that represents a close substitute for labour income. Since we observe changes in parental transfers only at the extensive margin, switching from positive to zero transfers, we assume that this variable reflects 
parents' latent desired transfer level, and that this changes monotonically with parental income, child labour supply, and child's labour market restrictions.

Youth respondents are also asked "Do you ever do any work in a spare-time paid job, even if it is only for an hour or two now and then? (Please don't include jobs you only do during the school holidays or voluntary work)". Those answering 'yes' are asked "How many hours on average do you usually work in this job (or jobs) during a term time week? Please include any hours you work at the weekend during term-time". These questions explicitly exclude unpaid or voluntary work, ensuring that a positive response is unambiguously associated with labour income. The term-time focus makes the crowding out of study time or other extra-curricular activities a salient concern.

\subsection{Employment of children in England}

The rules governing the employment of children in England are set by the Department for Education (see guidelines in DCSF, 2009). Children aged at least 13 but less than the school leaving age may undertake 'light' work, deemed as not being harmful to their health, safety or development. ${ }^{6}$ There are age-specific restrictions on the types and hours of work children may do. Those under 16 cannot work 'mainly or solely' for the sale of alcohol, for example. Those in compulsory education may work only 12 hours per week in term time, including a maximum of 2 hours on a weekday or Sunday; 8 hours on a Saturday ( 5 hours if under 15 years); one hour before school on a weekday; and none during school hours or after $7 \mathrm{pm}$ on a school night. Those employing children below the school leaving age must obtain the signature of a parent and a permit from the Local Education Authority, which must be satisfied that the child's education will not be damaged. Howieson et al. (2006) estimate that in Scotland only 11\% of children covered by this legislation had the required permit, so these regulations are poorly enforced.

\subsection{Descriptive statistics}

Table 1 shows descriptive statistics relating to employment, earnings and cash transfers from parents. The propensity to work rises as the children age, particularly among girls, who start from a lower base. Conditional on working, girls work longer hours than boys, but receive lower

\footnotetext{
${ }^{6}$ Full-time education is compulsory until the last Friday in June of the academic year when the child turns 16.
} 
earnings and hourly wages. The proportion receiving cash transfers declines very slightly with age, and is marginally higher for girls than boys.

Table 1: Descriptive statistics: Employment and transfer receipt by gender

\begin{tabular}{|c|c|c|c|c|c|c|}
\hline & \multicolumn{2}{|c|}{ Wave 1 (Age 14) } & \multicolumn{2}{|c|}{ Wave 2 (Age 15$)$} & \multicolumn{2}{|c|}{ Wave 3 (Age 16) } \\
\hline & Boys & Girls & Boys & Girls & Boys & Girls \\
\hline Employed (\%) & 24.9 & 18.9 & 28.3 & 27.1 & 29.0 & 31.2 \\
\hline Receive cash transfer (\%) & 80.9 & 81.7 & 77.8 & 79.4 & 76.7 & 78.4 \\
\hline $\begin{array}{l}\text { Mean hours employment }{ }^{2} \\
\text { (conditional on being employed) }\end{array}$ & $\begin{array}{c}4.14 \\
(0.10)\end{array}$ & $\begin{array}{c}4.24 \\
(0.11)\end{array}$ & $\begin{array}{c}5.16 \\
(0.13)\end{array}$ & $\begin{array}{c}5.38 \\
(0.10)\end{array}$ & $\begin{array}{c}6.44 \\
(0.15)\end{array}$ & $\begin{array}{c}6.72 \\
(0.13)\end{array}$ \\
\hline $\begin{array}{l}\text { Mean earnings }{ }^{2}, £_{\mathrm{S}} \\
\text { (conditional on being employed) }\end{array}$ & $\begin{array}{l}14.52 \\
(0.41)\end{array}$ & $\begin{array}{l}14.24 \\
(0.39)\end{array}$ & $\begin{array}{l}20.58 \\
(0.52)\end{array}$ & $\begin{array}{l}18.90 \\
(0.33)\end{array}$ & $\begin{array}{l}27.96 \\
(0.63)\end{array}$ & $\begin{array}{l}27.31 \\
(0.55)\end{array}$ \\
\hline Observations & 7116 & 7250 & 6258 & 6303 & 5815 & 5839 \\
\hline
\end{tabular}

Notes: All figures for hours and earnings are weekly. Standard errors in parentheses. Population means and proportions calculated using final probability weights. Standard errors clustered by school. ${ }^{1}$ : GCSE capped point score (calculated over best eight subjects). ${ }^{2}$ : Hours of employment and earnings are per week. ${ }^{3}$ : Key Stage 3 Average Point Score, standardized by subtracting mean and dividing by standard deviation.

Table 2 shows the differences in prior educational performance (age 14) and subsequent educational performance (age 16) according to the child's employment status in each year. At every stage, and for both boys and girls, those in employment are positively selected on age 14 educational performance, and go on to perform better at age 16 by a sufficient margin to widen future educational opportunities substantially. ${ }^{7}$ This relationship is driven by the positive correlation between factors determining employability and academic performance, such as individual motivation, relative age (Plug, 2001; Crawford et al., 2013), school quality, parental investments, and local labour market conditions.

Table 2 also shows that the gender wage gap is not driven by differential selection: Girls have superior prior educational performance and are more positively selected into employment according to these grades. Instead, these observations are consistent with boys and girls being active in distinct labour markets with different wage rates and factors restricting employment: Kooreman (2009) shows the in-school employment gender wage differential in the Netherlands is due to the concentration of girls in babysitting roles, for example. For this reason we estimate

\footnotetext{
${ }^{7}$ The difference in performance is equivalent to one GCSE grade in four of the student's best eight subjects. The threshold for continuation in full-time education is five A $^{*} \mathrm{C}$ grades. This is achieved by around $60 \%$ of students. Students typically take around 10 GCSE courses.
} 
Table 2: Descriptive statistics: Prior and subsequent educational performance by employment status

$\begin{array}{lcccc}\text { Wave } 1 & \text { (Age 14) } & \text { Wave } 2 \text { (Age 15) } & \text { Wave } 3 & \text { (Age 16) } \\ \text { Boys } & \text { Girls } & \text { Boys } \quad \text { Girls } & \text { Boys } & \text { Girls }\end{array}$

Standardized age 14 exam score ${ }^{3}$ by employment status

$\begin{array}{lcccccc}\text { If employed } & 0.097 & 0.293 & 0.096 & 0.302 & 0.114 & 0.302 \\ & (0.032) & (0.034) & (0.033) & (0.031) & (0.031) & (0.034) \\ \text { If not employed } & -0.101 & 0.019 & -0.090 & -0.009 & -0.094 & -0.015 \\ & (0.034) & (0.030) & (0.036) & (0.018) & (0.037) & (0.034)\end{array}$

\begin{tabular}{lcccccc} 
Mean age 16 & exam & score $^{3}$ & by employment status & & & \\
If employed & 294.31 & 328.06 & 295.07 & 331.37 & 299.44 & 334.50 \\
& $(3.35)$ & $(3.42)$ & $(3.47)$ & $(2.83)$ & $(2.83)$ & $(2.96)$ \\
If not employed & 276.75 & 303.62 & 277.41 & 301.36 & 276.39 & 300.91 \\
& $(3.50)$ & $(2.89)$ & $(3.57)$ & $(1.92)$ & $(3.69)$ & $(3.30)$ \\
\hline \multirow{2}{*}{ Observations } & 7116 & 7250 & 6258 & 6303 & 5815 & 5839 \\
\hline \hline
\end{tabular}

Notes: All figures for hours and earnings are weekly. Standard errors in parentheses. Population means and proportions calculated using final probability weights. Standard errors clustered by school. ${ }^{1}$ : GCSE capped point score (calculated over best eight subjects). ${ }^{2}$ : Hours of employment and earnings are per week. ${ }^{3}$ : Key Stage 3 Average Point Score, standardized by subtracting mean and dividing by standard deviation.

our models separately for males and females. ${ }^{8}$

Finally, Table 3 shows that employment and financial support are always negatively correlated. Parents are always more likely to make cash transfers to children who do not work, and children are always more likely to work if they do not receive cash transfers. This is consistent with children's working decision being financially motivated and with parents' use of financial transfers to disincentivise child employment.

\section{Estimation}

We estimate cross-sectional models of the observed counterparts to the parent-leading and childleading Stackelberg models. The econometric specification for the transfer and labour supply decisions are shown in equations (11-12) and (13-14). In this exposition the functions and error terms with superscript $S$ refer to an agent acting as a Stackelberg leader. The superscript $N$ refers to an agent taking the actions of the other as given, as in a Nash equilibrium or acting

\footnotetext{
${ }^{8}$ In addition to social norms about the types of jobs to be taken by boys and girls, there are rigid gender roles within certain ethnic groups which make employment among girls exceptionally rare, both in comparison to other ethnic groups and to boys of the same ethnic group. Appendix A.4, page 56, presents some descriptive statistics on both these topics.
} 
Table 3: Descriptive statistics: Negative correlation between child's part-time employment and parental transfers

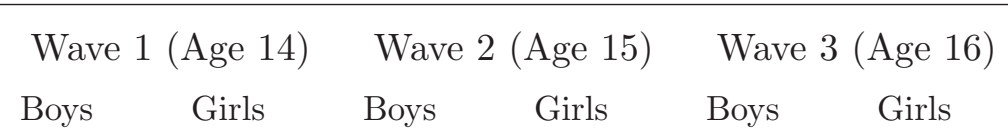

\section{Transfer receipt, \%, by employment status:}

\begin{tabular}{|c|c|c|c|c|c|}
\hline f employed & 71.5 & 73.3 & 66.3 & 71.1 & 63.2 \\
\hline If not employed & 83.9 & 83.6 & 82.4 & 82.6 & 82.0 \\
\hline
\end{tabular}

\section{Employment rates, \%, by transfer receipt}

\begin{tabular}{lllllll} 
If receives transfers & 22.0 & 17.0 & 24.2 & 24.3 & 23.1 & 26.8 \\
If does not receive transfers & 37.1 & 27.6 & 43.1 & 38.2 & 44.4 & 46.9 \\
\hline Observations & \multirow{2}{*}{7116} & \multirow{2}{*}{7250} & 6258 & 6303 & 5815 & \multirow{2}{*}{5839} \\
\hline
\end{tabular}
Notes: All figures for hours and earnings are weekly. Standard errors in parentheses. Population means and proportions calculated using
final probability weights. Standard errors clustered by school. ${ }^{1}$ : GCSE capped point score (calculated over best eight subjects). ${ }^{2}$ : Hours of employment and earnings are per week. ${ }^{3}$ : Key Stage 3 Average Point Score, standardized by subtracting mean and dividing by standard deviation.

as a Stackelberg follower.

The decision to estimate separately by wave rather than exploiting the panel nature of this dataset is made because the teenage years are a time of transition. Teenagers have very different labour market opportunities at age 16 than 13 . Time away from studying may be increasingly costly in terms of educational performance the closer the children get to the exams which will determine their future academic opportunities. Children will desire higher consumption and increasing independence over what they consume. For these reasons, we do not expect a stable relationship over time that conventional panel data methods are appropriate for. ${ }^{9}$ Moreover, this approach enables us to identify the effect of changing one contextual factor - the age of the children - on the parameters of the model. This is a key contribution to a literature in which several factors may be responsible for differences in previous findings.

\footnotetext{
${ }^{9}$ We use longitudinal weights to ensure that the estimates are obtained from the same sample of individuals at each wave and that the sample is representative of the population in terms of household demographics and parental background as measured at wave 1. See James et al. (2010) for details of the weights' construction.
} 


\subsection{Parent-leading Stackelberg model}

Equations (11-12) show the parent-leading Stackelberg model. Equation (11) represents the parent's transfer decision. Equation (12) represents the child's effective best correspondence.

$$
\begin{aligned}
& t=1 \quad \text { if } \quad t^{S}(M, \mathbf{Z}, \mathbf{X})+\epsilon_{t}^{S}>0 \\
& t=0 \quad \text { if } \quad t^{S}(M, \mathbf{Z}, \mathbf{X})+\epsilon_{t}^{S} \leq 0
\end{aligned}
$$

$$
\begin{array}{r}
L=L^{N}\left(t^{S}, \mathbf{Z}, \mathbf{X}\right)+\epsilon_{L}^{N} \quad \text { if } \quad L^{N}\left(t^{S}, \mathbf{Z}, \mathbf{X}\right)+\epsilon_{L}^{N}>0 \\
L=0 \quad \text { if } \quad L^{N}\left(t^{S}, \mathbf{Z}, \mathbf{X}\right)+\epsilon_{L}^{N} \leq 0
\end{array}
$$

Transfers and labour supply are subject to correlated random shocks due to unobservable heterogeneity in preferences, resources, and constraints such as discrete job offers and variation in travel time to school or work, such that:

$$
\left(\begin{array}{c}
\epsilon_{t}^{S} \\
\epsilon_{L}^{N}
\end{array}\right) \sim \mathcal{N}\left(\begin{array}{l}
0 \\
0
\end{array}\right),\left(\begin{array}{cc}
\sigma_{t}^{S} & \rho_{1} \\
\rho_{1} & \sigma_{L}^{N}
\end{array}\right)
$$

This system of a simultaneous probit and tobit is estimated using Full Information Maximum Likelihood (FIML). This system is identified through the exclusion of parental income, $M$ from the second stage (child's labour supply) equation. In other words, we assume that the probability of receiving a transfer is strictly increasing in parental income, but there is no direct effect of parent income on child's labour supply (Dustmann et al., 2009; Wolff, 2006; Kalenkoski and Pabilonia, 2010; and Gong, 2009). ${ }^{10}$

Variables expected to restrict the child's labour market opportunities, $\mathbf{Z}$ are included in both equations to enable us to test whether (i) these variables have the predicted effect on child labour supply, and (ii) the parent holds constant or reduces transfers in response to these labour demand conditions.

\footnotetext{
${ }^{10}$ The LSYPE uses a different measure of income in each sampling wave. In waves 1 and 3 the variable "Total income from work, benefits and anything else for [Main Parent] (and partner)" is elicited in 92 bands and 12 bands respectively. In wave 2, the "gross annual salary" of both parents and the "total annual amount of benefits received" are elicited separately, and other sources of income are omitted. Because these measures are not directly comparable, we use a 'relative permanent income' measure defined as the percentile (zero being the lowest, one being the highest) of the household's mean gross income percentile across the three waves, using imputed household income where necessary. Details of the imputation procedure can be found in James et al. (2010).
} 


\subsection{Child-leading Stackelberg model}

Equations (13-14) show the child-leading Stackelberg model. Equation (13) represents the child's labour supply decision, with the child accounting for the parent's transfer schedule. Equation (14) represents the parent's best response, or contingent transfer schedule:

$$
\begin{array}{r}
L=L^{S}(M, \mathbf{Z}, \mathbf{X})+\epsilon_{L}^{S} \text { if } L^{S}(M, \mathbf{Z}, \mathbf{X})+\epsilon_{L}^{S}>0 \\
L=0 \quad \text { if } L^{S}(M, \mathbf{Z}, \mathbf{X})+\epsilon_{L}^{S} \leq 0 \\
t=1 \quad \text { if } \quad t^{N}(L, M, \mathbf{X})+\epsilon_{t}^{N}>0 \\
t=0 \quad \text { if } \quad t^{N}(L, M, \mathbf{X})+\epsilon_{t}^{N} \leq 0
\end{array}
$$

We again assume the presence of correlated random shocks such that:

$$
\left(\begin{array}{c}
\epsilon_{t}^{N} \\
\epsilon_{L}^{S}
\end{array}\right) \sim \mathcal{N}\left(\begin{array}{l}
0 \\
0
\end{array}\right),\left(\begin{array}{cc}
\sigma_{t}^{N} & \rho_{2} \\
\rho_{2} & \sigma_{L}^{S}
\end{array}\right)
$$

This system is identified through the exclusion of labour market factors $\mathbf{Z}$ from the second-stage (parental transfer) equation.

We use three different ways to represent restrictions on the child's labour supply. First, the child's relative age within the academic cohort is included as a linear term, equal to 1 for September birthdays (the oldest in the cohort) up to 12 for those born the following August. Children born earlier in the academic year will be allowed to work longer hours or access specific job types earlier than their younger peers. This means they are better placed to fill suitable vacancies which arise in the autumn as temporary staff are taken on prior to Christmas, and members of older cohorts move away to university. The parent's attitude to financial support may however change when the child turns a year older, so we also control for the child being interviewed after their birthday within the academic year.

Secondly, we use the 2004 index of multiple deprivation (IMD) of the teenagers' area of residence as a proxy for very localized area characteristics determining a teenager's employment opportunities. The IMD measures the prevalence of deprivation within geographical areas containing 400-1200 households (Office of the Deputy Prime Minister, 2004). The index is calculated from 
aggregated individual-level deprivation indicators and area characteristics in seven domains: income; employment; health; education, skills and training; barriers to housing and services; crime; and the living environment. All these elements are expected to be correlated with youth labour market opportunities. Of greatest relevance in driving this relationship are (i) the area unemployment rate, and (ii) the average road distance to a post office and supermarket or convenience store. The latter are suitable potential employers and may also be clustered with other shops and businesses. The IMD is functionally dependent on the characteristics of the individual households observed in the LSYPE. To net out this effect we explicitly control for householdlevel counterparts to the componenents of the aggregated deprivation indicators recorded in the IMD. We assume that conditional on household circumstances (including parental employment and income and the child's prior educational performance) the local area characteristics captured by the IMD have no direct effect on the parent's transfer decision except via the child's employment opportunities.

Thirdly, we use the adult (aged 16-64) unemployment rate in the youth's local authority district (LAD) of residence at time of interview. There are 325 LADs in England, with an average population of 164,000. This variable therefore represents labour market opportunities over a wider geographic area. Conditional on the parents' own income and employment status we assume this has no direct effect on parent's transfer decision, except via the child's employment opportunities.

\subsection{Additional controls}

The vector of additional controls, $\mathbf{X}$, includes further variables expected to affect the parent's resource constraints, either agent's relative preference for human capital $\left(\kappa_{i}\right)$ or the child's labour market opportunities or endowment of human capital $(\mu)$. These comprise (i) socioeconomic characteristics, including parent's employment status and education; (ii) the child's prior educational performance and special educational needs (SEN) status; (iii) ethnicity dummies, to account for differing preferences and labour market discrimination; and (iv) household structure, which determines individual' material and time resources as well as preferences. We account for geographical and seasonal variation in labour market opportunities with dummies for urban-rural status, residence outside Greater London, and year and month of interview. 


\section{Results}

In this section, we first present the estimates obtained under the parent-leading Stackelberg framework. We show these are contrary to the predictions of the model in two ways. We then show results consistent with the child-leading Stackelberg mechanism being used instead. The complete maximum likelihood estimation output for both sexes and all waves is presented is Appendix A.6 (page 60). We focus on a few key variables and for ease of exposition refer to plots of marginal effects of key variables (with solid lines indicating $95 \%$ confidence intervals) in Figures 6-14. All coefficients in the transfer equation are presented as the average marginal effect on the probability of transfer. ${ }^{11}$

\subsection{Parent leading: Setting a 'fixed' transfer level}

The coefficients and standard errors for key variables in the parent-leading Stackelberg model are presented in Tables 4 (boys) and 5 (girls). The estimates for each wave are presented separately. The first column in each case shows the average marginal effects on the probability of the child receiving transfers. The second and third columns in each case showing tobit coefficients for effects on the child's labour supply assuming first exogeneity ("tobit") then endogeneity ("FIML 2nd stg") of labour supply to the parent's transfer decision. We first discuss results showing that our model is statistically identified, then show that child labour supply responds to labour demand conditions in the expected direction, before showing how parents' responses to these labour demand conditions means we can reject the parent-leading Stackelberg model.

\footnotetext{
${ }^{11}$ Any comparison between sexes is not 'other things equal', because of systematic differences in characteristics between these groups. Girls have higher prior educational performance and a lower incidence of special educational needs than boys, for example. The results should be interpreted as comparing average marginal effects based on a sample representative of the population of the group and time of interest.
} 


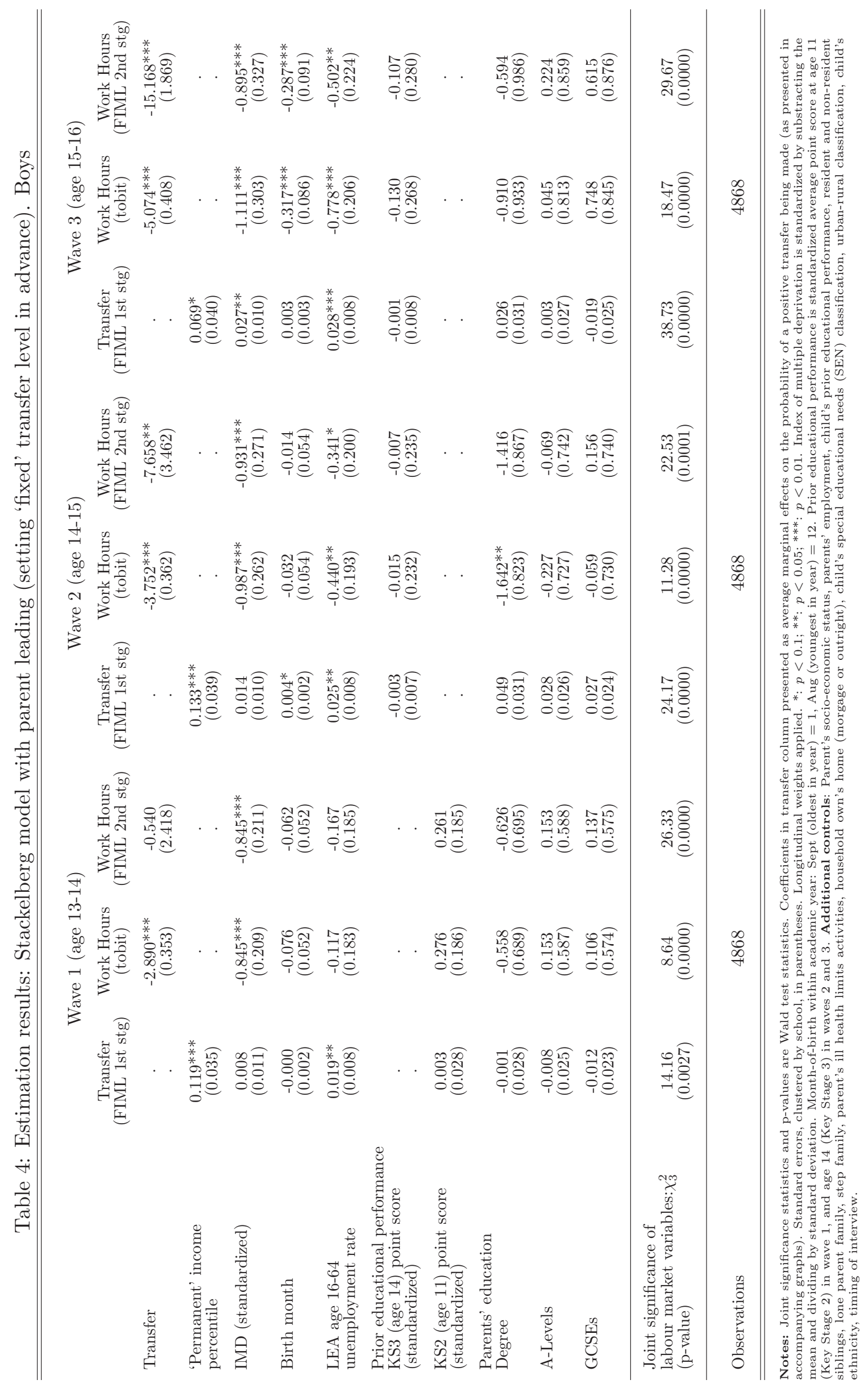




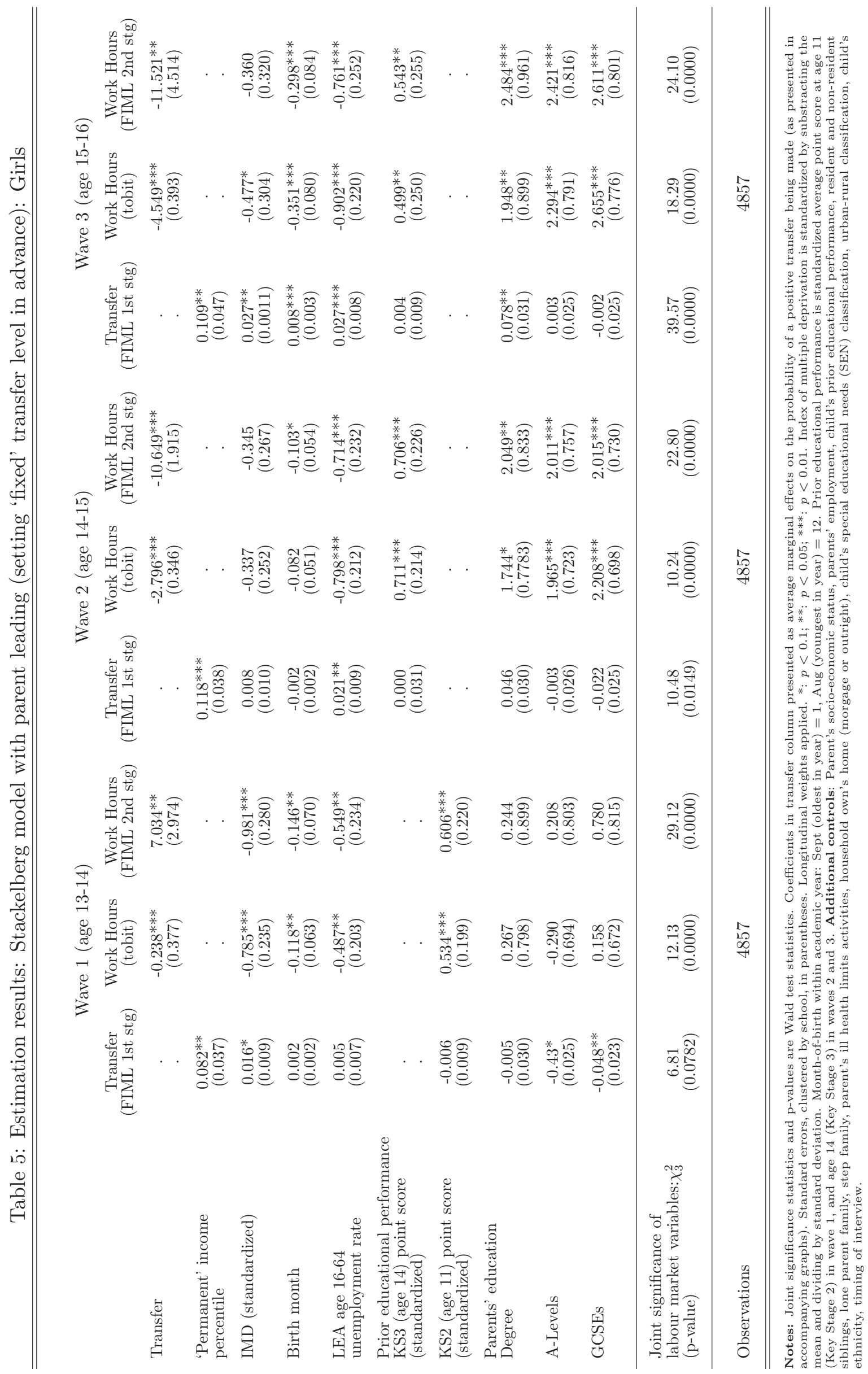




\subsubsection{Identification}

The second-stage coefficients representing the child's labour supply response to parental transfers are identified by the exclusion of parental income from the child's labour supply equation, and the probability of positive transfers strictly increasing in parental income. The second line of coefficients in Tables 4 and 5 (girls)Tables shows that the latter condition clearly holds. A 10 percentile move up the income distribution increases the probability of positive transfer by around 1 percentage point. This is statistically significant at the $5 \%$ level in five out of the six cases and at the $10 \%$ level in the last (boys in wave 3 ).

\subsubsection{Labour demand and child part-time work}

Figure 3 shows that being born later in the academic year produces a significant employment penalty for both boys and girls in wave 3 . While the coefficients are negative for earlier waves, they are not statistically significant. This is consistent with 'turning 16' specifically bringing the significant advantage in accessing the types of jobs systematically vacated by students departing for university. Figures 4 and 5 show that the IMD and adult unemployment rate always have a negative effect on predicted working hours. At least one of these coefficients is statistically significant at the $5 \%$ level in all six specifications, and when the wave 1 , wave 2 and wave 3 regression models are estimated simultaneously for each gender as 'Seemingly Unrelated' systems, the coefficients on both IMD and the unemployment rate are jointly significantly different from zero for both genders with $p<0.005$ in all cases.

\subsubsection{Testing the predictions of the Parent-leading Stackelberg model}

Inspecting both the child responses to parental transfers, and how parental transfers respond to labour demand conditions, our results are contrary to the predictions of the parent-leading Stackelberg model in two ways.

Firstly, Figure 6 shows that boys always reduce their working hours parental transfers increase, and this effect becomes larger as they become older. Girls also reduce their labour supply in response to parental transfers at both ages 15 and 16. Indeed, the effect is large enough that, on average, making transfers would crowd out all the teenager's working hours. However, labour supply is increasing in transfer receipt for girls in wave 1 . This coefficient has a p-value of 
Figure 3: Parent-leading Stackelberg

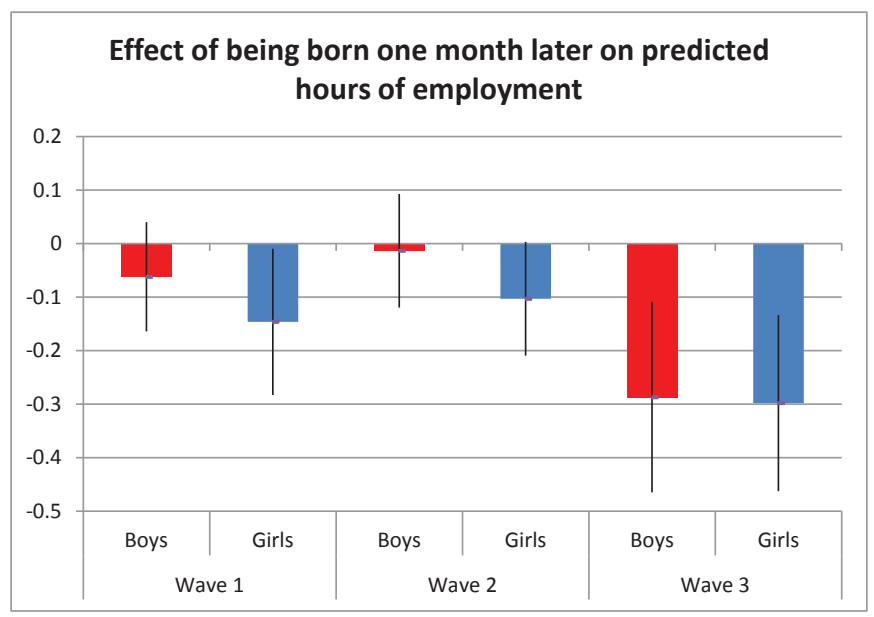

Figure 4: Parent-leading Stackelberg

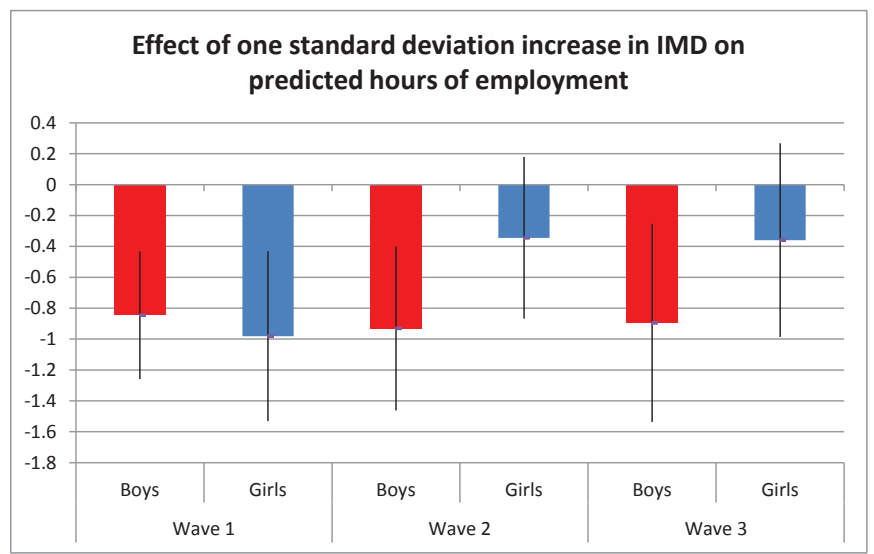

Figure 5: Parent-leading Stackelberg

Effect of one percentage point increase in age 16-64 LA unemployment rate on predicted hours of employment

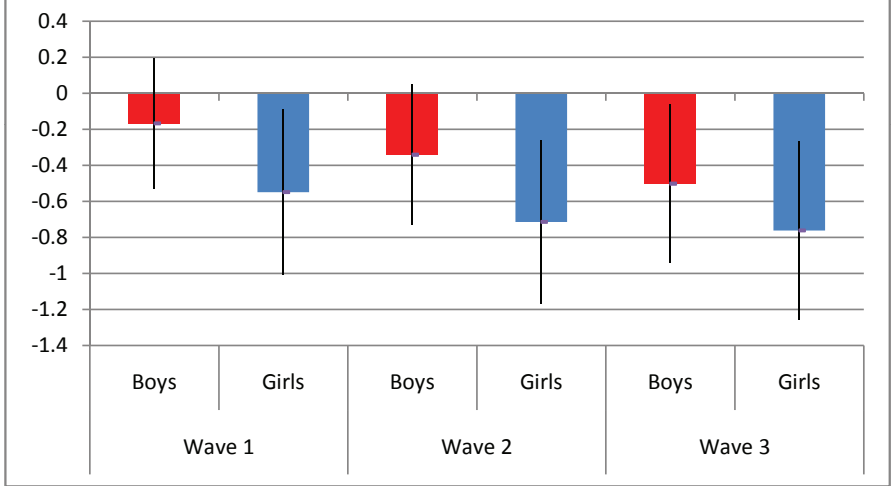


0.018 for a two-sided test. Accounting for testing for significant effects on multiple outcomes for each individual (i.e. their labour supply at each of three points in time), this result remains significant at the $10 \%$ level with a p-value of $0.065 .{ }^{12}$

It is possible that if girls' employment in this age-group largely consists of babysitting younger siblings, payment for this work may be conflated with transfers. We re-estimated the model for children with no younger siblings (for whom there should be no within-household babysitting work), and obtained a still positive, but much smaller and statistically insignificant coefficient, lending limited support to this hypothesis. We present these results and discuss the broader issue of distinguishing household and market work and present these results in full in Appendix A.5. The second and most important empirical finding at odds with the predictions of the parentleading Stackelberg model is that parents are shown to increase their probability of making cash transfers in response to the factors which restrict the child's labour market opportunities. As we discussed in section 2.4, the parent-leading Stackelberg model would predict that transfers are held constant or reduced in response to such factors.

Figure 6: Parent-leading Stackelberg

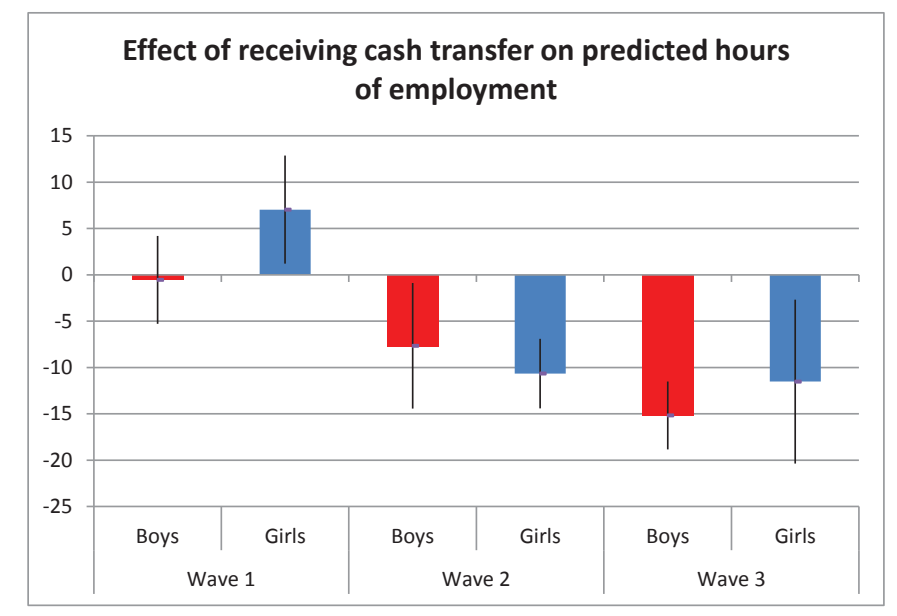

Figure 7 shows that parents never significantly reduce their probability of transfer for offspring who are younger within their cohort, and for girls in the year they turn 16, significantly increase the probability of transfer. (This result is robust to accounting for multiple testing of the same hypothesis over each of the three waves, with the initial p-value of 0.0004 adjusted to

\footnotetext{
${ }^{12}$ This calculation uses the following Bonferroni Adjustment method, with the adjusted p-value calculated as follows: $p_{a d j}=1-(1-p(k))^{g(k)}$ where $g(k)=M^{1-r(. k)}$. Here $M$ is the number of outcomes being tested (3 each for boys and girls), $p(k)$ is the unadjusted p-value for the $k^{\text {th }}$ outcome and $r(. k)$ is the mean of the (absolute) pairwise correlations between all the outcomes other than $k$ (i.e. the correlation between girls' labour supply in wave 2 and wave 3, which is 0.434). See Sankoh, Huque and Duby (1997), pp.2534-2535 for discussion and Aker et al. (2011) for an economics application.
} 
Figure 7: Parent-leading Stackelberg

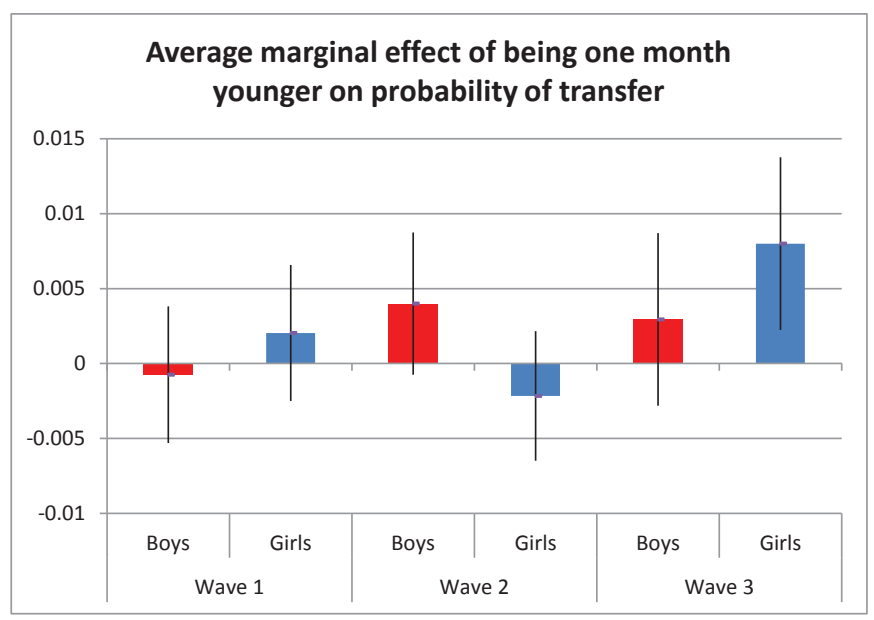

Figure 8: Parent-leading Stackelberg

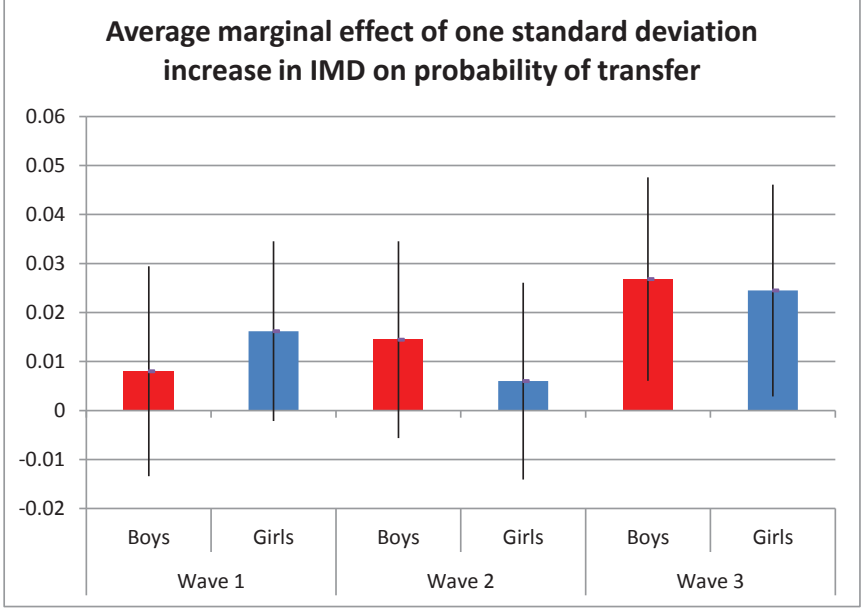

Figure 9: Parent-leading Stackelberg

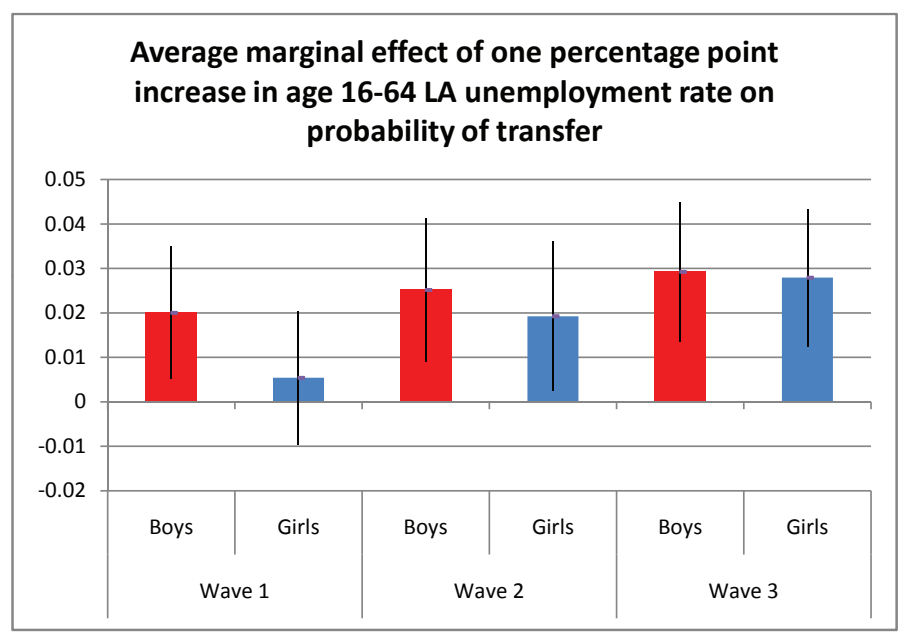


0.0018). ${ }^{13}$ We cannot infer whether the absence of a corresponding effect for boys, for whom the employment penalty is equally large, is due to systematically different treatment - parents acting more altruistically, in terms of insuring their consumption, towards their daughters than sons - or statistical imprecision.

In addition, Figures 8 and 9 show that the local Index of Multiple Deprivation and unemployment rate always have a positive effect on the probability of transfer. Both are statistically significant for wave 3, and the unemployment rate coefficient is statistically significant at the $5 \%$ level in all other cases except for girls in wave 1 . The average marginal effects across the waves are jointly significantly different from zero for the unemployment rate for both genders (boys, $p=0.002$; girls, $p=0.003)$, and significant for the IMD for boys $(p=0.035)$ though marginally insignificant for girls $(p=0.072) .{ }^{14}$

These findings show that parents' behaviour is not time-consistent and not opportunistic in relation to a ceiling on the child's hours of employment. We therefore reject a parent-leading Stackelberg model for the determination of child's labour supply. This may mean that the difficulty for the child to obtain and keep a job presents too often and heavy a challenge to time-consistent behaviour by the parent. Alternatively, the parent may give too low a weight to his own consumption relative to elements of the child's utility, and to child's consumption relative to human capital, for this decision-making process to make him best off. Either way, it seems parents prefer to 'insure' their child's consumption against labour market difficulties outside their control (Ermisch, 2003, p.5).

\subsection{Child leading, or parent setting a contingent transfer schedule}

We now present results for the child-leading Stackelberg framework, in which shifts in the child's labour supply decision identify the parent's best-response correspondence. Coefficients and standard errors for key variables are presented in Tables 6 (boys) and 7 (girls), and again the estimates for each wave are presented separately. The first column in each case shows tobit coefficients for the effect on the child's labour supply. The second and third columns in each case show average marginal effects on the probability of the child receiving transfers assuming

\footnotetext{
${ }^{13}$ Using the same Bonferroni Adjustment method as described in footnote 13 , with $M=3$ and $r(. k)=0.3143$

${ }^{14}$ These findings show that the IMD is not acting as a proxy for unobserved household level characteristics with which it is correlated. If this were the case, one would expect a negative sign, because generally the more affluent the household, and hence the greater the probability of the transfer, the lower the IMD. As such, we are confident that by including household level counterparts to the deprivation indicators captured by the IMD, the coefficients here represent the contextual effect of local labour market conditions.
} 
first exogeneity ("probit") then endogeneity ("FIML 2nd stg") of transfers to the child's labour supply decision. Again, we first present results showing that our model is statistically identified, before showing how parents' best response correspondence is a function of household income and the child's labour supply.

\subsubsection{First stage: Labour supply equation}

The parent's best response correspondence is identified by changes in the child's labour supply driven by labour demand factors which we assume have no direct effect on parental transfers, conditional on the household and area characteristics for which we also control. Figures 10-12, and the third, fourth and fifth lines of coefficients in Tables 6 and 7 show that the unemployment rate, IMD and month of birth on labour supply all have the expected negative effect on child labour supply. Within each gender and wave, they are always jointly significant at the the 5\% level or less. These graphs also support the decision to estimate seperately by wave and sex. Both boys and girls become progressively more responsive to the adult unemployment rate as they get older. While the difference in coefficients is not statistically significant, boys appear better insulated from this wider adult labour market, instead (at least at ages 15 and 16) being dependent on very localised determinants of opportunities, proxied by the IMD. Turning 16 (in wave 3) earlier than one's peers is the only birthday that matters significantly for employment opportunities. This suggests that jobs this birthday opens up; involving alcohol or catering; are more common among vacancies created by 18 year-olds leaving for university than those for which the lifting of the 5-hour Saturday restriction (on one's 15th birthday) would be employers' binding concern. 


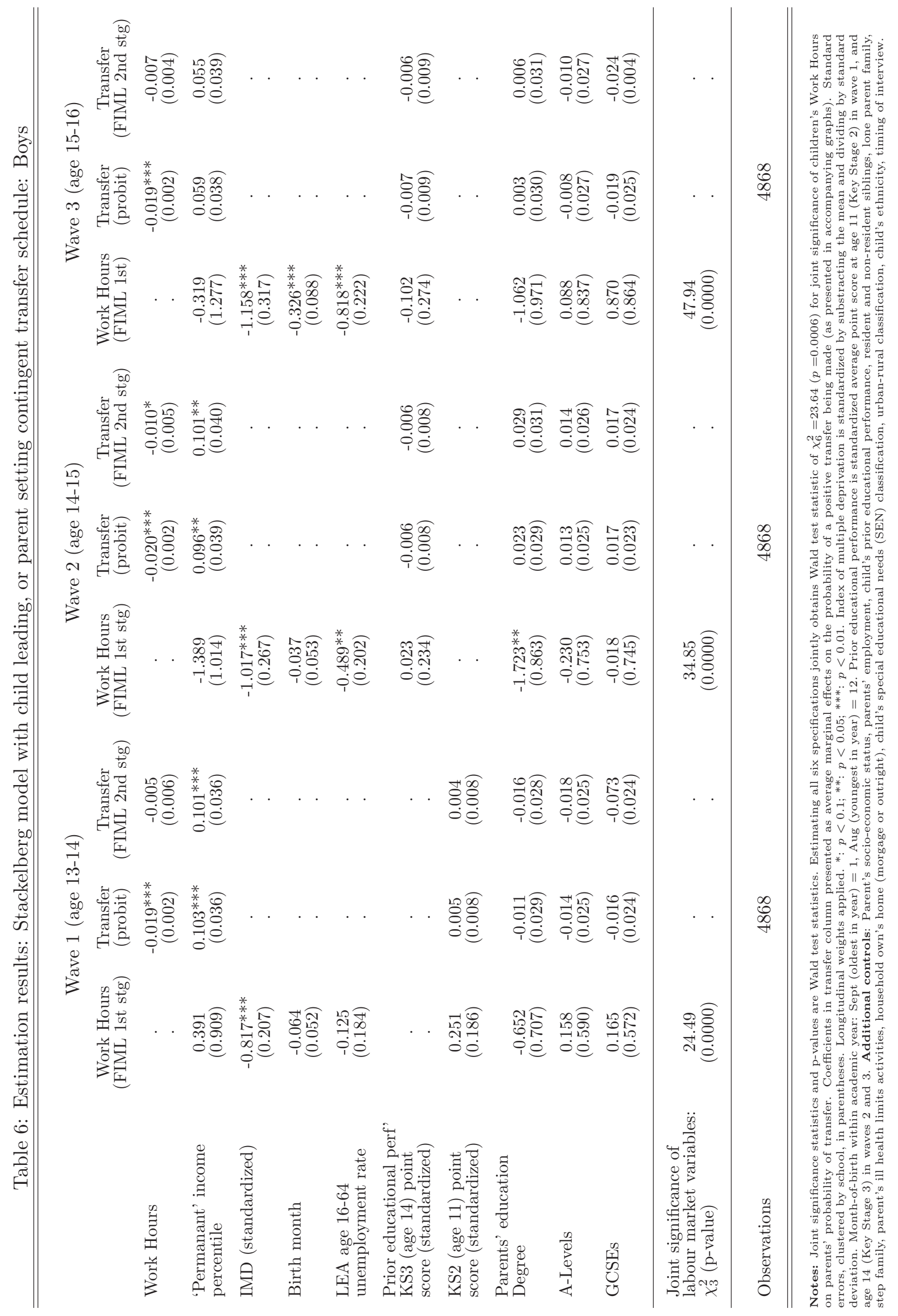




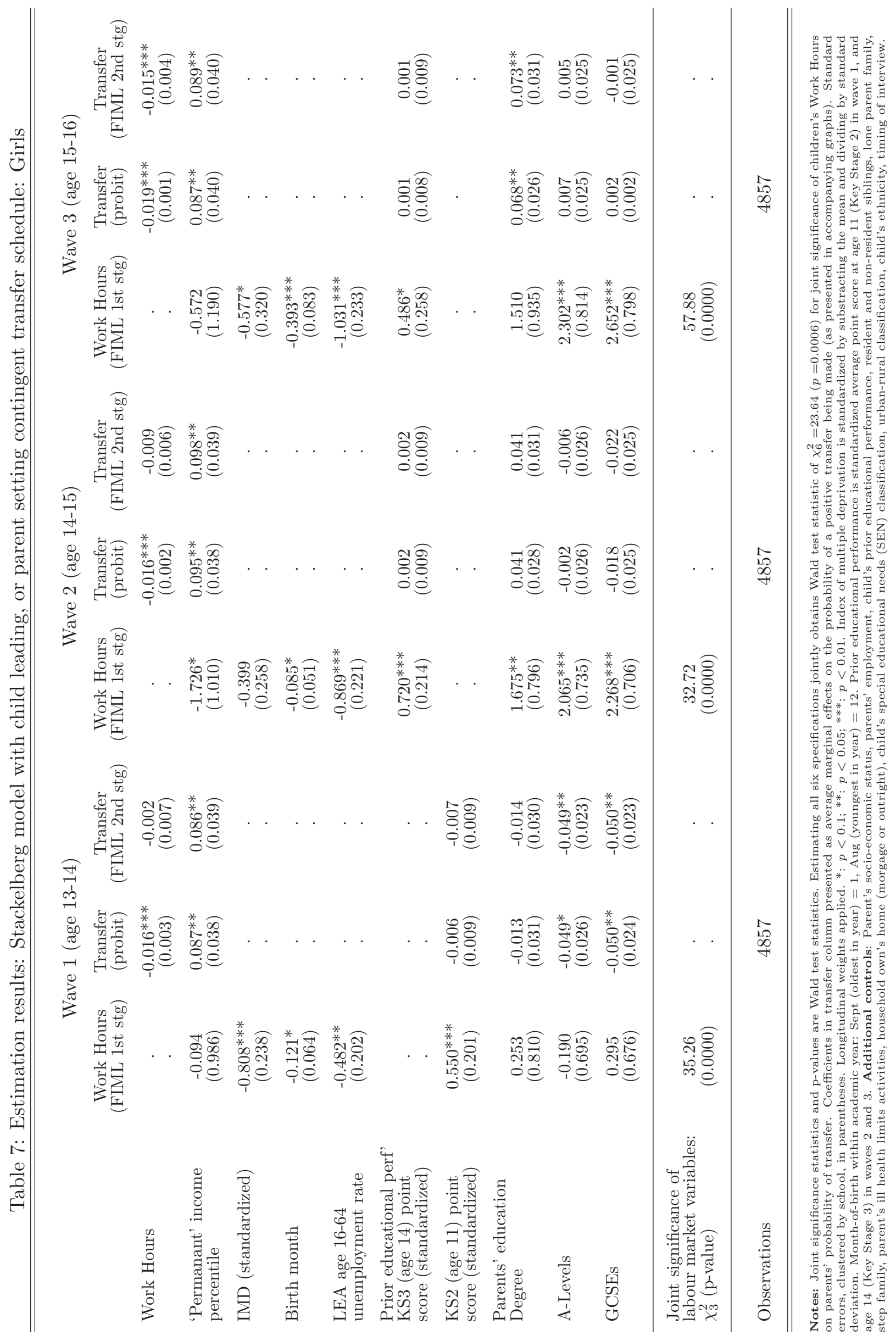


Figure 10: Child-leading Stackelberg

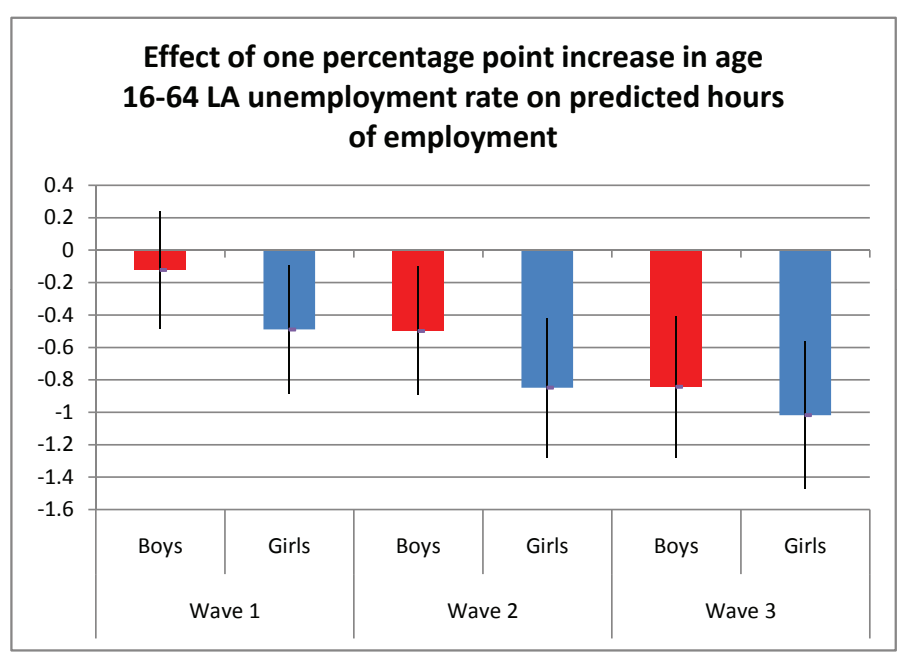

Figure 11: Child-leading Stackelberg

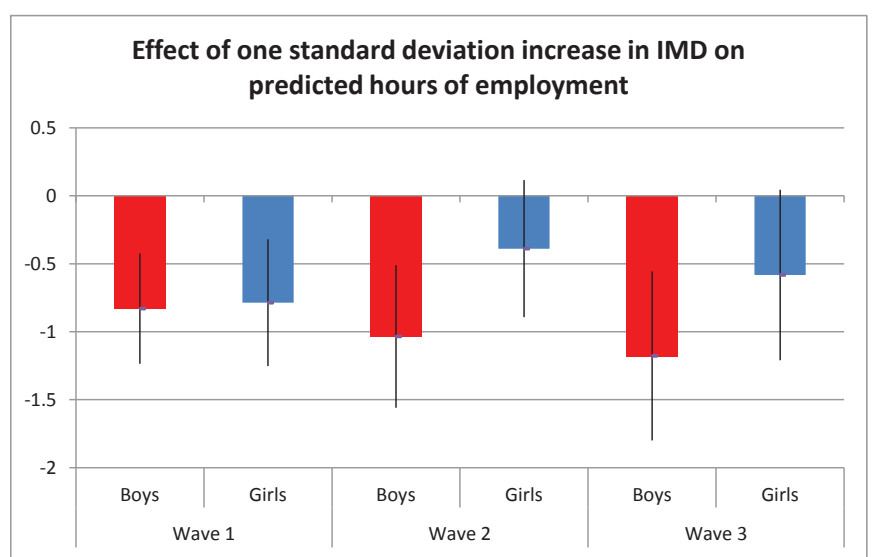

Figure 12: Child-leading Stackelberg

Effect of being born one month later on predicted hours of employment

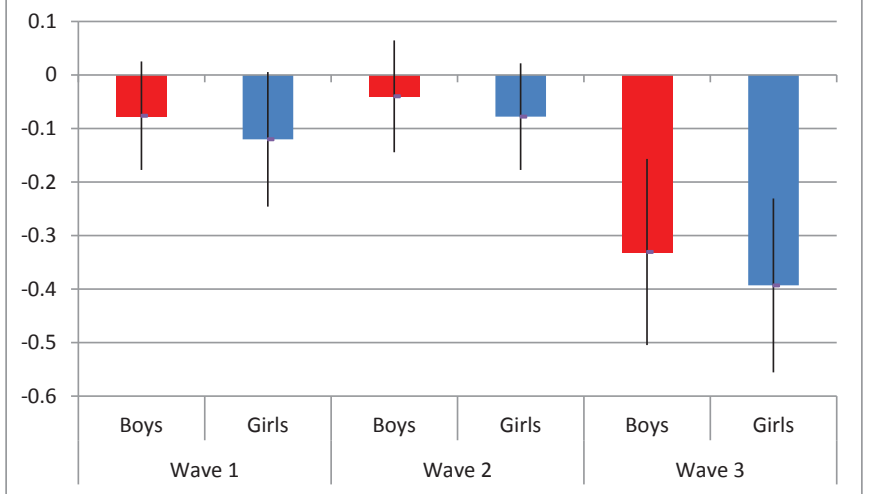




\subsubsection{Second stage: Parent's transfer or tax schedule}

Figure 13 shows that parent's transfer probability is always increasing in household income. The effect is small, akin to a 10 percentage point movement up the income distribution increasing the probability of transfers by approximately 1 percentage point. We expected a small magnitude for the income gradient. Earlier work by Dustmann et al. (2009) and Dustmann and Micklewright (2001) identified a marginal propensity for parents to transfer income to their children of just 0.005 on average, for example. With transfers somewhat inelastic with respect to parental income, this is consistent with Dustmann et al's (1996) argument that youths from lower-income households do not face "disproportionately high financial pressure" to work. ${ }^{15}$

Figure 14 shows that transfer probability is always decreasing in hours of employment, but this effect is statistically significant only for girls in wave 3, which is the final year of compulsory education. This result is robust to adjusting for our testing of multiple null hypotheses (in this case, that the coefficient on hours of work is zero in each of three time periods). The initial p-value of 0.0012 becomes 0.0041 after making this adjustment. ${ }^{16}$ As such, for this final group, we can firmly reject the null hypothesis that parents do not tax their children. More generally, when wave 1, wave 2 and wave 3 regression models for each gender are estimated simultaneously as 'Seemingly Unrelated' systems, these 'tax rate' coefficients across all three waves are jointly significantly less than zero at the $1 \%$ level for girls $(\mathrm{p}=0.0038)$ but and $10 \%$ level for boys $(\mathrm{p}=0.0563)$.

These conclusions are clearly affected by the fact that we have information on the extensive margin only (i.e. whether there is a transfer from parents to children or not). There could be adjustments on the intensive margin (the amount), but as these changes are not observable our statistical power to detect parents' behavioural responses is limited. Our estimates here tell us simply that the 'tax rate' at the intensive margin is sufficiently shallow to mean that increasing labour supply results in very few cases of parents switching from positive to zero transfers. Parents are sufficiently altruistic and paternalistic to adopt this decision-making mechanism in preference to setting a 'fixed' transfer level, but since they are not observed to discourage employment through a heavy 'tax rate', these results imply they do not perceive having a job

\footnotetext{
${ }^{15}$ A potential alternative strategy was to identify the effect of income changes over time on transfers. This proved infeasible due to the differences in income measurement between waves.

${ }^{16}$ Here we use the same Bonferroni Adjustment method described in footnote 13. The number of outcomes being tested is again 3 , and $r(. k)$, the mean of the (absolute) pairwise correlations between all the outcomes other than $k$ (i.e. the correlation between girls' cash transfer receipt in wave 1 and wave 2 ) is 0.452
} 
to be particularly damaging to the child's human capital or educational performance.

Figure 13: Child-leading Stackelberg

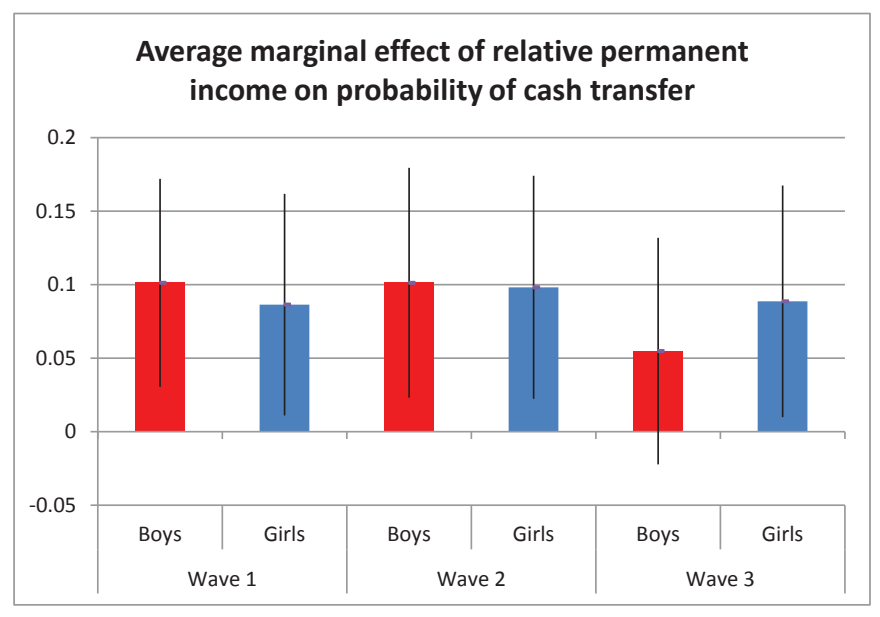

Figure 14: Child-leading Stackelberg

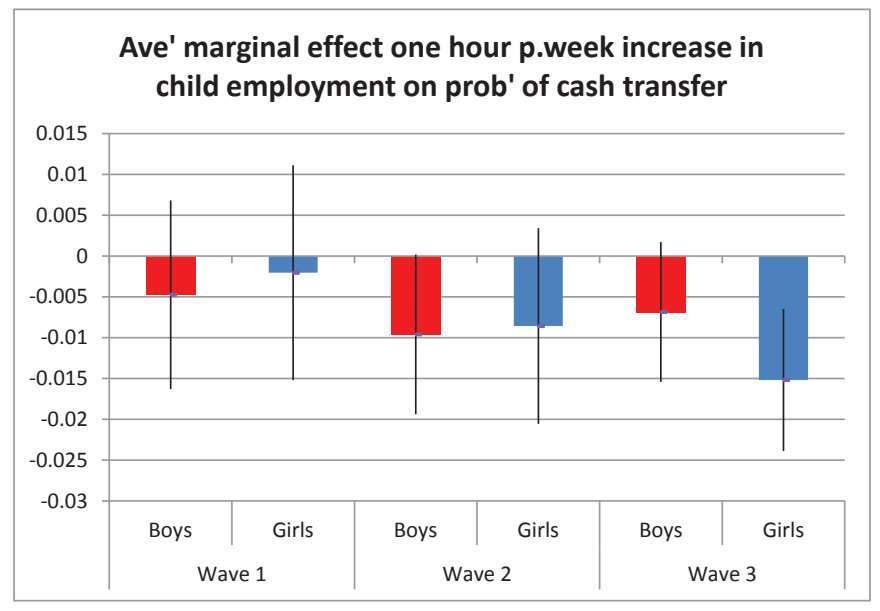

Nevertheless, we might expect the productivity of study time, in terms of educational performance measured at the end of school year 11, to be highest in that final year of compulsory schooling; and the amount of study time undertaken also to be highest close to these final exams, resulting in the greatest scope for study time being crowded out. Certainly, it has been shown that the net effect of in-school employment is more detrimental to academic performance in closer proximity to examinations (Ruhm, 1997; Payne, 2004). In this case, we would expect parents' incentive to use their financial resources to deter in-school employment, and hence our ability to detect such a tax schedule, to be highest in the final year of compulsory education. The results in Figure 14 are consistent with this prediction, though also imply that, at least for work undertaken during this final year, parents perceive the net effect of in-school labour supply 
to be more detrimental for girls than boys. ${ }^{17}$ This may be because girls dominate employment in 'child-oriented' roles such as babysitting (Kooreman, 2009), which may contribute more to family-oriented and less to career-oriented skills and preferences, resulting in less favourable long-run labour market outcomes due to changes in fertility decisions, for example (Erdogan et al., 2012). An alternative explanation is that parents have a higher relative preference for education-oriented human capital in their daughters than sons, perhaps reflecting women's higher wage returns to educational qualifications (Machin, 2005; Bonesrønning, 2010). ${ }^{18}$

\section{Conclusion}

Employment experience for teenagers in compulsory education has a potentially significant impact on educational performance and subsequent academic and labour market opportunities. This paper has focused on the idea that parents can use financial incentives to alter their child's decision to work, and developed a theoretical model for the interaction determining the financial support provided by parents and part-time employment taken by children. We motivate two alternative Stackelberg frameworks. In the first (parent-leading), parents set their transfer level in advance, anticipating the child's best-response. In the second (child leading) parents set a contingent transfer schedule for each level of labour supply, effectively taxing their children's earnings.

We test our model using data on a cohort of English teenagers between 2004 and 2006, estimating cross-sectional models for the same sample of individuals at ages 14, 15, and 16. Holding constant the institutional arrangements, education system and time-invariant unobserved characteristics, we identify significant differences in the determinants of selection into employment

\footnotetext{
${ }^{17}$ The results in Holford (2016), estimated using the same cohort of individuals, suggest that such an expectation would be rational. Most previous literature either focuses exclusively on males, in order that longer-run labour market outcomes may be considered without fertility considerations, or does not allow for heterogeneous effects by gender. The extant evidence is inconclusive. Ruhm (1997) suggests the human capital benefit of in-school employment is greater for females but D'Amico (1984) shows the opposite conclusion, while Rothstein (2007) shows similar and small negative effects for both genders.

${ }^{18}$ In this approach, we have implicitly assumed the same decision-making process is adopted by all households. However, as we note in section 2.3, the less paternalistic and more selfish is the parent, the more likely it is that she will prefer to set a fixed transfer level. Heterogeneous preferences may therefore lead to heterogeneity in the decision-making mechanism. Recognizing this, strictly speaking, our results show only that a sufficiently large proportion of parents adopt the child-leading model that the parent-leading model can be rejected in statistical terms. In Appendix A.1 (page 44), we derive the predictions of the model assuming the parent gains no utility from human capital, and show estimates for two subpopulations of potential policy interest: households in which the parent (i) would like the child to leave full-time education at the minimum age and (ii) has no qualifications. Though hampered by small samples, these estimates provide tentative evidence for these households moving from the parent-leading to child-leading mechanism between ages 14 and 16.
} 
as the children age, but do not detect significant differences in the propensity of parents to 'tax' their children's earnings over this time.

Estimates from the empirical counterpart to the parent-leading framework show that parents use their relative financial power to 'insure' their child's consumption against factors beyond their control. Rather than holding transfers constant in response to factors affecting the child's labour market opportunities, or reducing them in response to a ceiling being placed on their hours of employment, parents raise transfers instead. This suggests that parents would like their children to provide for their own consumption, but will not penalize them if this proves difficult. We also demonstrate a very shallow income gradient in parent's willingness to make cash transfers to the child. These results suggest that parents of children who otherwise would leave education at 16 can and will accommodate the two additional years of schooling which, from 2013-2014, have been becoming compulsory in the UK, as an 'extension to childhood', rather than impose a financial burden on an 'independent adult'. This should ensure the benefits to extended compulsory education will not be hindered by financial pressures to take employment.

These results are inconsistent with a model in which parents set a 'fixed' transfer level. We therefore reject the parent-leading Stackelberg framework. The findings are in line with a situation in which parents set a contingent transfer schedule for each possible level of the child's labour supply. In the language of game theory this can be interpreted as the parent - whose financial resources afford the choice between the two decision-making mechanisms - being better off by ceding the Stackelberg first-move advantage to the child. The child's human capital is a public good, valued by both the parent and the child but potentially eroded by long hours of employment. In this framework, by taxing the child's earnings the parent forces the child to internalise this social cost. This cannot be achieved with a fixed lump-sum transfer.

We find that the probability of receiving transfers is always decreasing in the child's hours of employment, so parents do tax their children, though this is only significant for girls in the final year of compulsory schooling. Further work should try to explore whether this gender distinction is due to gender differences in parental perceptions of the education production function or gender-specific parental preferences for education-oriented human capital.

Our results suggest there is little case for more restrictive regulation of in-school employment on equity grounds. There is strong positive selection into employment by prior educational 
performance, and the shallow income gradient in parental transfers reveals no evidence that consumption pressures drive low socio-economic status children into employment. Nevertheless, from the perspective of a social planner, it may still be the case that parents underestimate the human capital cost of employment, leading to sub-optimal outcomes. 


\section{References}

Aker, J., Boumnijel, R., McClelland, A., Tierney, N., 2011. Zap it to me: The impacts of a mobile cash transfer program. Center for Global Development Working Paper 268.

Antman, F., 2012. Elderly care and intrafamily resource allocation when children migrate. Journal of Human Resources 47 (2), 331-363.

Apps, P., Rees, R., 1996. Labour supply, household production and intra-family welfare distribution. Journal of Public Economics 60, 199-219.

Apps, P., Rees, R., 2009. Public Economics and the Household. Cambridge University Press, Cambridge, United Kingdom.

Ashworth, A., Ulph, D., 2011. Household models. In: Brown, C. (Ed.), Taxation and Labour Supply. Vol. 33. Allen and Unwin, pp. 117-133.

Becker, G., 1974. A theory of social interactions. Journal of Political Economy 82 (6), 1063-1093.

Becker, G., 1981. Altruism in the family and selfishness in the market place. Economica 48 (189), $1-15$.

Bell, C., Fesbach, H., Schneider, M., 2012. Raising juveniles. Games and Economic Behavior $74,32-51$.

Bergstrom, T. C., 1989. A fresh look at the rotten kid theorem - and other household mysteries. Journal of Political Economy 97 (5), 1138-1159.

Bingley, P., Walker, I., 2013. There's no such thing as a free lunch: Evidence on altruism and agency from household expenditure responses to child nutrition programs. Review of Economics of the Household 5, 371-392.

Blundell, R., Chiappori, P.-A., Meghir, C., 2005. Collective labor supply with children. Journal of Political Economy 113 (6), 1277-1306.

Bonesrønning, H., 2010. Are parental effort allocations biased by gender? Education Economics $18(3), 253-268$.

Bourguignon, F. J., 1999. The cost of children: may the collective approach to household behaviour help? Journal of Population Economics 12 (4), 503-522. 
Browning, M., Chiappori, P., 1998. Efficient intra-household allocations: A general characterisation. Econometrica 66 (6), 1241-1278.

Bruce, N., Waldman, M., 1991. Transfers in kind: why they can be efficient and nonpaternalistic. American Economic Review 81 (5), 1345-1351.

Bucciol, A., Veronesi, M., 2014. Teaching children to save: What is the best strategy for lifetime savings? Journal of Economic Psychology 45, 1-17.

Bureau of Labor Statistics, 2000. Report on the youth labor force.

Burton, P., Phipps, S., Curtis, L., 2002. All in the family: A simultaneous model of parenting style and child conduct. American Economic Review 92 (2), 368-372.

Buscha, F., Maurel, A., Page, L., Speckesser, S., 2011. The effect of high school employment on educational attainment: A conditional difference-in-differences approach. Oxford Bulletin of Economics and Statistics 74 (3), 380-396.

Collins, W., 1990. Parent-child relationships in the transition to adolescence: Continuity and change in interaction, affect, and cognition. In: Montemayor, R., Adams, G., Gullotta, T. (Eds.), From childhood to adolescence: A transitional period? Advances in adolescent development. Vol. 2. Sage, Thousand Oaks, CA, pp. 85-106.

Collins, W., Gleason, T., Sesma, Jr, A., 1997. Internalization, autonomy, and relationships: Development during adolescence. In: Grusec, J., Kuczynski, L. (Eds.), Parenting and childrens internalization of values: A handbook of contemporary theory. Wiley, New York, pp. 78-99.

Collins, W., Luebker, C., 1994. Parent and adolescent expectancies: Individual and relationship significance. In: Smetana, J. (Ed.), Beliefs about parenting: Origins and developmental implications. New Directions for Child Development. Vol. 66. Jossey-Bass, San Francisco, CA, pp. $65-80$.

Conti, G., Pudney, S. E., 2011. Survey design and the analysis of satisfaction. Review of Economics and Statistics 93 (3), 1087-1093.

Crawford, C., Dearden, L., Greaves, E., 2013. When you are born matters: Evidence for England. Institute for Fiscal Studies Report R80. 
D'Amico, R., 1984. Does employment during high school impair academic progress? Sociology of Education 57, 152-164.

Dauphin, A., El Lahga, A.-R., Fortin, B., Lacroix, G., 2011. Are children decision-makers within the household? Economic Journal 121, 871-903.

Department for Children, Schools and Families, 2009. Guidance on the employment of children. Department for Children, Schools and Families: https://www.education.gov.uk/ publications/eOrderingDownload/Child_employment09.pdf, accessed 24-08-2012.

Department for Education, National Centre for Social Research, May 2013. Longitudinal Study of Young People in England: Waves One to Seven, 2004-2010: Secure Access. computer file, 2nd Edition. Colchester, Essex: UK Data Archive [distributor], May 2013. SN: 7104.

Dustmann, C., Micklewright, J., 2001. Intra-household transfers and the part-time work of children. CEPR discussion papers 2796.

Dustmann, C., Micklewright, J., Rajah, N., Smith, S., 1996. Earning and learning: Educational policy and the growrth of part-time work by full-time pupils. Fiscal Studies 17 (1), 79-103.

Dustmann, C., Micklewright, J., van Soest, A., 2009. In-school labour supply, parental transfers and wages. Empirical Economics 37 (1), 201-218.

Erdogan, Z., Jacobson, J., Kooreman, P., 2012. Do babysitters have more kids? The effects of teenage work experiences on adult outcomes. IZA Discussion Papers 6856.

Ermisch, J., 2003. An Economic Analysis of the Family. Princeton University Press, Princeton NJ.

Gong, T., 2009. Do parental transfers reduce youths' incentives to work? Labour: Review of Labour Economics and Industrial Relations 23 (4), 653-676.

Holford, A., 2016. Youth employment and academic performance: production functions and policy effects. IZA Discussion Papers 10009.

Hotz, V. J., Xu, L. C., Tienda, M., Ahituv, A., 2002. Are there returns to the wages of young men from working while in school? The Review of Economics and Statistics 84 (2), 221-236.

Howieson, C., McKechnie, J., Semple, S., 2006. The nature and implications of the part-time employment of secondary school pupils. Scottish Executive Social Research. 
James, N., Silva, P., Smith, P., 2010. Implementing a strategy to compensate for missing data in the Longitudinal Study of Young People in England. Tech. rep., ORC International for the Department for Children, Schools, and Families.

Kalenkoski, C. M., Pabilonia, S. W., 2010. Parental transfers, student achievement and the labor supply of college students. Journal of Population Economics 23 (2), 469-496.

Konrad, K. A., Lommerud, K. E., 1995. Family policy with non-cooperative families. Scandinavian Journal of Economics 97 (4), 581-601.

Kooreman, P., 2009. The early inception of labor market gender differences. Labour Economics $16,135-139$.

Kooreman, P., Kapteyn, A., 1990. On the empirical implementation of some game theoretic models of household labour supply. Journal of Human Resources 25, 584-598.

Leonard, R., 104. Reading Cournot, reading Nash: The creation and stabilisation of the Nash equilibrium. Economic Journal 104, 492-511.

Leuthold, J., 1968. An empirical study of formula income transfers and the work decision of the poor. Journal of Human Resources 3, 312-323.

Light, A., 2001. In-school work experience and the returns to schooling. Journal of Labor Economics 19 (1), 65-93.

Lillydahl, J. H., 1990. Academic achievement and part-time employment of high school students. Journal of Economic Education 21 (3), 307-316.

Lindbeck, A., Weibull, J., 1988. Altruism and time consistency: the economics of fait accompli. Journal of Political Economy 96 (6), 1165-1182.

Lundberg, S., Romich, J. L., Tsang, K. P., 2009. Decision-making by children. Review of Economics of the Household 7, 1-30.

Machin, S., 2005. Wage inequality since 1975. In: Dickens, R., Gregg, P., Wadsworth, J. (Eds.), The Labour Market under New Labour: The state of working Britain. Palgrave Macmillan, pp. 191-200.

McElroy, M., Horney, M., 1981. Nash bargained household decisions: towards a generalization of the theory of demand. International Economic Review 22 (2), 333-349. 
Montmarquette, C., Viennot-Briot, N., Dagenais, M., 2007. Dropout, school peformance and working while in school. Review of Economics and Statistics 89 (4), 752-760.

Oettinger, G. S., 1999. Does high school employment affect high school academic performance. Industrial and Labor Relations Review 53 (1), 136-151.

Office of the Deputy Prime Minister, 2004. The English Indices of Deprivation 2004: Summary (revised). http://webarchive.nationalarchives.gov.uk/20120919132719/www . communities.gov.uk/documents/communities/pdf/131206.pdf, accessed 25-07-2013.

Payne, J., 2004. The impact of part-time jobs in years 12 and 13 on qualification achievement. British Educational Research Journal 29 (4), 599-611.

Plug, E., 2001. Season of birth, schooling and earnings. Journal of Economic Psychology 22, 641-660.

Rothstein, D., 2007. High school employment and youths' acadmic achievement. Journal of Human Resources 42 (1), 194-213.

Ruhm, C. J., 1997. Is high school employment consumption or investment? Journal of Labor Economics 15 (4), 735-776.

Sankoh, A., Huque, M., Dubey, S., 1997. Some comments on frequently used multiple endpoint adjustment methods in clinical trials. Statistics in Medicine 16, 2529-2542.

Schmidt, K., 1993. Reputation and equilibrium characterization in repeated games with conflicting interests. Econometrica 61 (2), 325-351.

Shim, S., Barber, B., Card, N., Xiao, A., Serido, J., 2010. Financial socialization of first year college students. the roles of parents, work, and education. Journal of Youth and Adolescence $39,1457-1470$.

Steinberg, L., 2001. We know some things: Adolescent-parent relationships in retrospect and prospect. Journal of Research on Adolescence 11, 1-19.

Tyler, J. H., 2003. Using state child labor laws to identify the effect of school-year work on high school achievement. Journal of Labor Economics 21 (2), 381-408.

Wolff, F.-C., 2006. Parental transfers and the labor supply of children. Journal of Population Economics 19 (4), 853-877. 


\section{A Appendix}

\section{A.1 Parents with no preference for human capital}

The theoretical predictions in the main body of this paper are driven by the assumption that the parent is paternalistic; she cares more about the child's human capital than does the child himself. This enables us to reject the Nash equilibrium on welfare grounds, and our empirical results suggest that parents' relative preference for human capital is sufficiently high for them to prefer to set a contingent transfer schedule based on the child's labour market earnings, rather than a fixed transfer level. Thus, it is the parent's preference for human capital that drives her to 'insure' the child's consumption against labour market factors outside the child's control.

In this appendix, we show how the predictions of the model change when the parent does not care about the child's human capital. We show that in this case, in common with conventional non-cooperative games, she will prefer to move first and set a fixed transfer level, thus no longer insuring the child's consumption. We test the same predictions of the parent-leading Stackelberg model for two subpopulations that may be expected to have a lower preference for human capital than the pooled population: parents who declare that they would like their child to leave full-time education at age 16; and parents with no educational qualifications. We find tentative evidence that parents in these groups transition from the parent-leading to the child-leading model between the child's ages of 14 and 16, suggesting either that the parent's relative preference for human capital, or their perception of the negative human capital effect of in-school employment, increases over time.

\section{A.1.1 Parent's maximisation problem}

The parent's maximisation problem under a Nash equilibrium or when she acts as a Stackelberg follower, in either case taking the child's action as given, is now as follows:

$$
\max _{t} U^{p}=U^{p}\left(P(M-t), C(w L+t), \kappa_{p}(\mathbf{X})\right)
$$

Because in these cases, she takes the child's action $(L)$ as given, her optimality condition is unchanged:

$$
U_{C}^{p}=U_{P}^{p}
$$


Acting as a Stackelberg leader, the parent must account for the indirect effects of $t$ on the utility from consumption, but no longer from the child's human capital, caused by the child's labour supply response to $t$ :

$$
\max _{t} U^{p}=U^{p}\left(P(M-t), C\left(w L^{*}(t)+t\right), \kappa_{p}(\mathbf{X})\right)
$$

The parent's optimality condition as a Stackelberg leader is, hence:

$$
U_{C}^{p}\left(1+\frac{\partial L^{*}}{\partial t} \cdot w\right)=U_{P}^{p}
$$

Since the child's maximisation problems and optimality conditions are unchanged, he will still reduce labour supply in response to increasing transfers, so $\frac{\partial L^{*}}{\partial t}<0$. This means, at the Nash equilibrium level of transfers it holds that:

$$
U_{C}^{p}\left(1+\frac{\partial L^{*}}{\partial t} \cdot w\right)<U_{P}^{p}
$$

From this position, a parent who does not care about the child's human capital will reduce transfers, thereby increasing her own consumption (and reducing its marginal utility $U_{P}^{p}$ ) and reducing the child's (increasing his marginal utility $U_{C}^{c}$ ). This means that the parent-leading Stackelberg equilibrium will occur at lower transfers and higher labour supply than the Nash equilibrium.

This situation can again be represented graphically, as shown in Figure 15. There are two key differences from the situation portrayed in Figure 1. Firstly, since the parent now will now never subsidise employment in order to encourage human capital accumulation, there is no range of labour supply over which the parent increases transfers in response to increased labour supply. This means that $\frac{\partial t^{*}}{\partial L}<0$ for all $L$, not only in equilibrium, so the parent's BR is downward sloping over its entire range. Secondly, the parent's bliss point is now above the child's bestresponse correspondence, meaning that the parent-leading Stackelberg model is strictly preferred to the Nash equilibrium, in turn strictly preferred to the child-leading Stackelberg equilibrium. The child's preference ordering is precisely the opposite (Since the child's optimality condition is unchanged, the child-leading Stackelberg equilibrium will still occur at higher labour supply and lower transfers than the Nash equilibrium). 
Figure 15: Agents' optimisation problem and the three equilibria when the parent has no preference for child's human capital

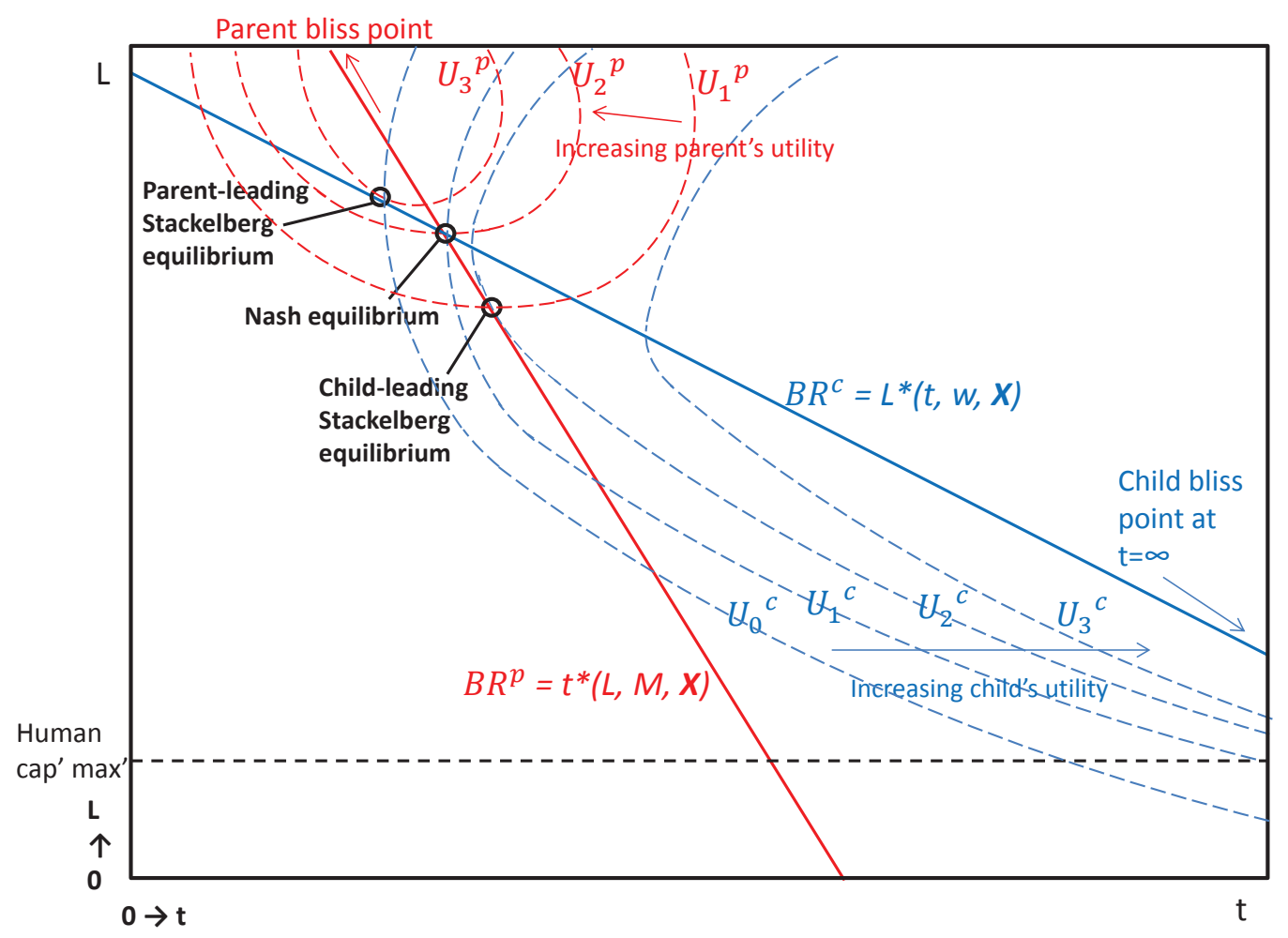

\section{A.2 Estimates}

Our estimates of the parent-leading model are shown in Tables A1 and A2, and the child-leading model in Tables A3 and A4. In each case, the results for the group whose parents would like them to leave full-time education at 16 is shown in the upper panel, those whose parents have no qualifications in the lower panel, and in both cases boys first.

In the parent-leading model we must first note that in three cases (for sons of parents who would like them to leave at 16 , in waves 2 and 3 , and daughters of parents with no qualifications, in wave 1), the coefficient on 'permanent' income is negative. Though in these cases the effect is not significant, the positive coefficients obtained in the majority of other cases also fail to obtain significance. This means that the effect of transfers on labour supply in the second stage of these models is not identified. Nevertheless, by focusing on the first stage results we are able to test the prediction of the parent leading model that the parent reduces or does not alter transfers in response to labour market difficulties faced by the child.

For the group whose parents would like them to leave full-time education, among boys we fail to reject this hypothesis in wave 1 . Indeed, there is strong evidence that parents are less likely to 
give transfers to children who are younger within the school year (having controlled for month of interview, including a dummy for interview after the child's birthday). In wave 2, we again fail to reject the hypothesis, but in wave 3 , it is firmly rejected due the statistically significant positive coefficient on the LAD unemployment rate.

For girls, in wave 1 we find a positive coefficient on IMD, which is significant at the $5 \%$ level, but conversely, a negative coefficient on the cusp of significance at the $10 \%$ level, for the unemployment rate, though it should also be noted that for this sample, the effect of this unemployment rate on hours of employment is positive but not statistically different from zero. This suggests tentative grounds to reject the parent-leading model, but in wave 2 there is no such evidence. In wave 3 , the coefficients on IMD, birth month and unemployment are all positive, with the coefficient on birth month individually and the three coefficients jointly significant at the $10 \%$ level, meaning that there are again grounds to reject the parent-leading model. (Note the especially small sample for this specification, with which a $10 \%$ rejection is relatively more acceptable).

For those whose parents have no qualifications the picture is simpler. For boys the parentleading model cannot be rejected in wave 1, there are grounds for rejection in wave 2 (a $5 \%$ significant positive coefficient on unemployment, though the three variables together are not collectively significant), and a firmer rejection in wave 3 , due to the $1 \%$ significant coefficient on IMD. For girls, we always reject the parent-leading model, firmly in waves 1 and 3 , less so in wave 2 , where the coefficient on birth month is in fact negative (with a t-statistic of 1 ), but on the other two is positive and on the cusp of significance).

Moving to the child-leading model, the counterpart testable prediction is that we should obtain a negative coefficient on Work Hours in the parent's transfer equation. The failure to obtain statistical significance in the main body of the paper with the larger sample suggests obtaining robust inference on this hypothesis is challenging.

Nevertheless, at face value, we observe a positive (though never signifcant at any level) coefficient on Work Hours in the Transfer equation in three cases, all for girls; in waves 1 and 2 among those whose parents wanted them to leave education, and in wave 1 among those whose parents have no qualifications. In the former two cases, we failed to reject the parent-leading model, while in the last the parent leading model was rejected somewhat strongly. We observe a negative coefficient at the $5 \%$ level only for girls whose parents want them to leave, in wave 3 of the survey, which is consistent with the results in the main body of this paper. 
Altogether, therefore, the results presented in this section show that, even if parents' stated attitude places a low weight on educational human capital (since they would prefer their child to leave full-time education as soon as possible), by the time the child reaches the final year of compulsory schooling their observed behaviour is sufficient to reject the parent-leading model and consistent with setting a contingent transfer level, or 'taxing' their children. This means that despite their stated preference, they still care sufficiently about the effects of labour supply on immediate educational performance to prefer this strategy over setting a 'fixed' transfer level. However, there is some tentative evidence that, unlike the general population, while the children are aged 14 or 15, parents may prefer to set a fixed transfer level.

Our interpretation of this finding is that, at age 14, this subpopulation cares less about human capital than the general population, but this preference increases over time as the importance of educational qualifications for early labour market opportunities becomes more salient. 
Table A1: Estimation results for subpopulation of parents who would like child to leave full-time education at age 16: Parent-leading model

\begin{tabular}{|c|c|c|c|c|c|c|}
\hline & \multicolumn{6}{|c|}{ Boys } \\
\hline & \multicolumn{2}{|c|}{ Wave 1 (age 14 ) } & \multicolumn{2}{|c|}{ Wave 2 (age 15$)$} & \multicolumn{2}{|c|}{ Wave 3 (age 16 ) } \\
\hline & $\begin{array}{l}\text { Transfer } \\
\text { (1st stg) }\end{array}$ & $\begin{array}{l}\text { Work Hours } \\
\text { (2nd stg) }\end{array}$ & $\begin{array}{l}\text { Transfer } \\
\text { (1st stg) }\end{array}$ & $\begin{array}{l}\text { Work Hours } \\
\text { (2nd stg) }\end{array}$ & $\begin{array}{l}\text { Transfer } \\
\text { (1st stg) }\end{array}$ & $\begin{array}{l}\text { Work Hours } \\
\text { (2nd stg) }\end{array}$ \\
\hline Transfer & . & $\begin{array}{l}-6.375 \\
(4.259)\end{array}$ & . & $\begin{array}{l}-10.249 \\
(10.034)\end{array}$ & . & $\begin{array}{r}-15.917 \\
(5.685)\end{array}$ \\
\hline $\begin{array}{l}\text { 'Permanent' income } \\
\text { percentile }\end{array}$ & $\begin{array}{c}0.110 \\
(0.076)\end{array}$ & . & $\begin{array}{l}-0.228 \\
(0.082)\end{array}$ & . & $\begin{array}{l}-0.121 \\
(0.076)\end{array}$ & . \\
\hline IMD (standardized) & $\begin{array}{l}-0.004 \\
(0.019)\end{array}$ & $\begin{array}{l}-0.613 \\
(0.416)\end{array}$ & $\begin{array}{c}0.021 \\
(0.021)\end{array}$ & $\begin{array}{r}-0.961^{*} \\
(0.536)\end{array}$ & $\begin{array}{c}0.011 \\
(0.022)\end{array}$ & $\begin{array}{c}0.186 \\
(0.659)\end{array}$ \\
\hline Birth month & $\begin{array}{l}-0.017 * * * \\
(0.005)\end{array}$ & $\begin{array}{l}-0.101 \\
(0.134)\end{array}$ & $\begin{array}{c}0.005 \\
(0.005)\end{array}$ & $\begin{array}{l}-0.047 \\
(0.139)\end{array}$ & $\begin{array}{l}-0.009 \\
(0.006)\end{array}$ & $\begin{array}{l}-0.587^{* * *} \\
(0.218)\end{array}$ \\
\hline $\begin{array}{l}\text { LAD age } 16-64 \\
\text { unemployment rate }\end{array}$ & $\begin{array}{c}0.022 \\
(0.017)\end{array}$ & $\begin{array}{c}0.141 \\
(0.367)\end{array}$ & $\begin{array}{l}0.016 \\
(0.016)\end{array}$ & $\begin{array}{l}-0.246 \\
(0.465)\end{array}$ & $\begin{array}{c}0.056^{* * *} \\
(0.019)\end{array}$ & $\begin{array}{l}-0.968 \\
(0.619)\end{array}$ \\
\hline $\begin{array}{l}\text { Joint significance of labour } \\
\text { market variables: } \chi_{3}^{2}(p \text {-value })\end{array}$ & $\begin{array}{l}13.20 \\
(0.004)\end{array}$ & $\begin{array}{c}2.74 \\
(0.433)\end{array}$ & $\begin{array}{c}4.55 \\
(0.208)\end{array}$ & $\begin{array}{c}4.90 \\
(0.179)\end{array}$ & $\begin{array}{c}15.94 \\
(0.001)\end{array}$ & $\begin{array}{c}9.61 \\
(0.022)\end{array}$ \\
\hline Observations & \multicolumn{2}{|c|}{981} & \multicolumn{2}{|c|}{1077} & \multicolumn{2}{|c|}{1034} \\
\hline
\end{tabular}

\section{Girls}

Wave 1 (age 14)

(2nd stg)

Transfer

'Permanent' income percentile

IMD (standardized)

0.103

(0.139)

$0.057^{* *}$

(0.024)

Birth month

0.006

(0.008)

$-0.045^{1}$

LAD age 16-64

unemployment rate

(0.027)

Joint significance of labour

market variables: $\chi_{3}^{2}$ (p-value)
4.94

(0.176)
Wave
Transfer
(1st stg)

(2nd stg)

2.297

(9.038)

$-19.712^{* * *}$

(3.204)

0.020

(0.083)

$-0.368$

(0.889)

$-0.256$

$(0.205)$

0.021

(0.029)

.

0.240

(1.004)

$-0.002$

(0.006)

$-0.126$

$(0.204)$
0.297

$(0.804)$

0.037

$(0.022)$

$-0.525$

$(0.864)$

5.05

(0.168)

0.72

(0.868)

$(0.573)$
485

(0.059)

Wave 3 (age 16)

Transfer Work Hours

(1st stg) (2nd stg)

. $\quad-10.103$

$-0.151$

(0.133)

0.023

(0.036)

$-1.618^{*}$

(0.963)

$0.018^{*} \quad-0.287$

$(0.009) \quad(0.302)$

$0.039 \quad-0.357$

$(0.027) \quad(0.736)$

482

447

Notes: ${ }^{1}:$ p-value $=0.101$. So on margin of statistical significance. Joint significance statistics and p-values are Wald test statistics. Coefficients in transfer column presented as average marginal effects on the probability of a positive transfer being made. Standard errors, clustered by school, in parentheses. Longitudinal weights applied. *: $p<0.1 ; * *: p<0.05 ; * *: p<0.01$. Index of multiple deprivation is standardized by substracting the mean and dividing by standard deviation. Month-of-birth within academic year: Sept (oldest in year) = 1, Aug (youngest in year) $=12$. Prior educational perfor in year) $=12$. Prior educational performance is standardized average point score at age 11 (Key Stage 2) in wave 1 , and age 14 (Key Stage 3) in waves 2 and 3. Additional controls: Parent's highest qualification, parent's socio-economic status, parents' employment, child's prior educational performance, resident and non-resident siblings, lone parent family, child's special educational needs (SEN) classification, urban-rural classification, child's ethnicity, timing of interview. 
Table A2: Estimation results for subpopulation of parents who have no qualifications: Parentleading model

\begin{tabular}{|c|c|c|c|c|c|c|}
\hline & \multicolumn{6}{|c|}{ Boys } \\
\hline & \multicolumn{2}{|c|}{ Wave 1 (age 14 ) } & \multicolumn{2}{|c|}{ Wave 2 (age 15$)$} & \multicolumn{2}{|c|}{ Wave 3 (age 16 ) } \\
\hline & $\begin{array}{l}\text { Transfer } \\
\text { (1st stg) }\end{array}$ & $\begin{array}{l}\text { Work Hours } \\
\text { (2nd stg) }\end{array}$ & $\begin{array}{l}\text { Transfer } \\
\text { (1st stg) }\end{array}$ & $\begin{array}{l}\text { Work Hours } \\
\text { (2nd stg) }\end{array}$ & $\begin{array}{l}\text { Transfer } \\
\text { (1st stg) }\end{array}$ & $\begin{array}{l}\text { Work Hours } \\
\text { (2nd stg) }\end{array}$ \\
\hline Transfer & . & $\begin{array}{l}11.663 \\
(5.097)\end{array}$ & . & $\begin{array}{c}12.086 \\
(17.988)\end{array}$ & . & $\begin{array}{l}-13.033 \\
(7.684)\end{array}$ \\
\hline $\begin{array}{l}\text { 'Permanent' income } \\
\text { percentile }\end{array}$ & $\begin{array}{l}0.128 \\
(0.081)\end{array}$ & . & $\begin{array}{l}0.046 \\
(0.144)\end{array}$ & . & $\begin{array}{c}0.073 \\
(0.120)\end{array}$ & . \\
\hline IMD (standardized) & $\begin{array}{c}0.016 \\
(0.023)\end{array}$ & $\begin{array}{c}-2.358^{* * *} \\
(0.690)\end{array}$ & $\begin{array}{c}0.004 \\
(0.026)\end{array}$ & $\begin{array}{l}-0.378 \\
(1.267)\end{array}$ & $\begin{array}{c}0.065^{* * *} \\
(0.026)\end{array}$ & $\begin{array}{l}-0.427 \\
(1.219)\end{array}$ \\
\hline Birth month & $\begin{array}{l}-0.002 \\
(0.006)\end{array}$ & $\begin{array}{l}-0.041 \\
(0.200)\end{array}$ & $\begin{array}{c}0.001 \\
(0.007)\end{array}$ & $\begin{array}{l}-0.164 \\
(0.357)\end{array}$ & $\begin{array}{l}-0.004 \\
(0.008)\end{array}$ & $\begin{array}{l}-0.622 \\
(0.431)\end{array}$ \\
\hline $\begin{array}{l}\text { LAD age } 16-64 \\
\text { unemployment rate }\end{array}$ & $\begin{array}{c}0.010 \\
(0.018)\end{array}$ & $\begin{array}{c}0.130 \\
(0.547)\end{array}$ & $\begin{array}{c}0.048^{* *} \\
(0.024)\end{array}$ & $\begin{array}{l}-1.950 \\
(2.047)\end{array}$ & $\begin{array}{c}0.034 \\
(0.022)\end{array}$ & $\begin{array}{c}0.079 \\
(0.801)\end{array}$ \\
\hline $\begin{array}{l}\text { Joint significance of labour } \\
\text { market variables: } \chi_{3}^{2} \text { (p-value) }\end{array}$ & $\begin{array}{c}1.85 \\
(0.605)\end{array}$ & $\begin{array}{c}12.34 \\
(0.006)\end{array}$ & $\begin{array}{c}5.47 \\
(0.141)\end{array}$ & $\begin{array}{c}1.45 \\
(0.694)\end{array}$ & $\begin{array}{c}16.26 \\
(0.001)\end{array}$ & $\begin{array}{c}3.12 \\
(0.374)\end{array}$ \\
\hline Observations & & 806 & & 727 & & 731 \\
\hline
\end{tabular}

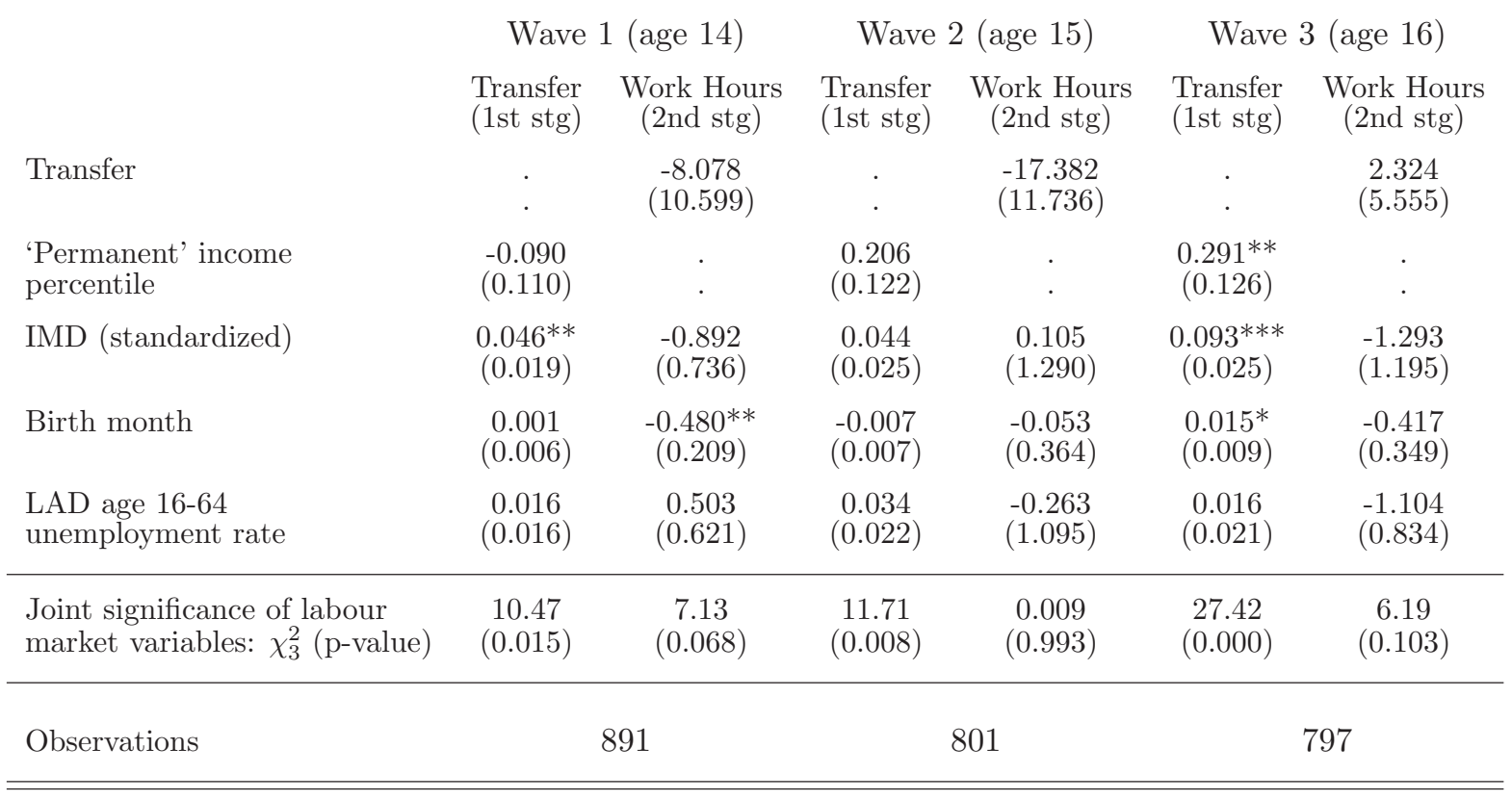

Notes: ${ }^{1}:$ p-value $=0.101$. So on margin of statistical significance. Joint significance statistics and p-values are Wald test statistics. Coefficients in transfer column presented as average marginal effects on the probability of a positive transfer being made. Standard errors, clustered by school, in parentheses. Longitudinal weights applied. *: $p \leq 0.1 ; * *: p \leq 0.05 ; * * * p \leq 0.01$. Index of multiple deprivation is standardized by substracting the mean and dividing by standard deviation. Month-of-birth within academic year: Sept (oldest in year) = 1, Aug (youngest in year) $=12$. Prior educational performance is standardized average point score at age 11 (Key Stage 2) in wave 1 , and age 14 (Key Stage 3) in waves 2 and 3. Additional controls: Parent's highest qualification, parent's socio-economic status, parents' employment, child's prior educational performance, resident and non-resident siblings, lone parent family, child's special educational needs (SEN) classification, urban-rural classification, child's ethnicity, timing of interview. 
Table A3: Estimation results for subpopulation of parents who would like child to leave full-time education at age 16:: Child-leading model

\begin{tabular}{|c|c|c|c|c|c|c|}
\hline & \multicolumn{6}{|c|}{ Boys } \\
\hline & \multicolumn{2}{|c|}{ Wave 1 (age 14 ) } & \multicolumn{2}{|c|}{ Wave 2 (age 15$)$} & \multicolumn{2}{|c|}{ Wave 3 (age 16 ) } \\
\hline & $\begin{array}{l}\text { Transfer } \\
\text { (1st stg) }\end{array}$ & $\begin{array}{l}\text { Work Hours } \\
\text { (2nd stg) }\end{array}$ & $\begin{array}{l}\text { Transfer } \\
\text { (1st stg) }\end{array}$ & $\begin{array}{l}\text { Work Hours } \\
\text { (2nd stg) }\end{array}$ & $\begin{array}{l}\text { Transfer } \\
\text { (1st stg) }\end{array}$ & $\begin{array}{l}\text { Work Hours } \\
\text { (2nd stg) }\end{array}$ \\
\hline Work Hours & . & $\begin{array}{l}-0.012 \\
(0.013)\end{array}$ & . & $\begin{array}{l}-0.011 \\
(0.009)\end{array}$ & . & $\begin{array}{l}-0.002 \\
(0.010)\end{array}$ \\
\hline $\begin{array}{l}\text { 'Permanant' income } \\
\text { percentile }\end{array}$ & $\begin{array}{l}-0.985 \\
(1.746)\end{array}$ & $\begin{array}{c}0.097 \\
(0.077)\end{array}$ & $\begin{array}{c}0.080 \\
(1.927)\end{array}$ & $\begin{array}{l}-0.040 \\
(0.079)\end{array}$ & $\begin{array}{l}4.150^{*} \\
(2.477)\end{array}$ & $\begin{array}{l}-0.097 \\
(-0.002)\end{array}$ \\
\hline IMD (standardized) & $\begin{array}{l}-0.592 \\
(0.407)\end{array}$ & . & $\begin{array}{c}-1.099^{* *} \\
(0.507)\end{array}$ & . & $\begin{array}{c}0.187 \\
(0.651)\end{array}$ & . \\
\hline Birth month & $\begin{array}{l}-0.008 \\
(0.137)\end{array}$ & . & $\begin{array}{l}-0.088 \\
(0.124)\end{array}$ & . & $\begin{array}{c}-0.476^{* *} \\
(0.210)\end{array}$ & . \\
\hline $\begin{array}{l}\text { LAD age } 16-64 \\
\text { unemployment rate }\end{array}$ & $\begin{array}{c}0.027 \\
(0.368)\end{array}$ & . & $\begin{array}{l}-0.405 \\
(0.415)\end{array}$ & . & $\begin{array}{c}-1.499^{* *} \\
(0.652)\end{array}$ & . \\
\hline $\begin{array}{l}\text { Joint significance of labour } \\
\text { market variables: } \chi_{3}^{2}(p \text {-value })\end{array}$ & $\begin{array}{c}2.57 \\
(0.463)\end{array}$ & . & $\begin{array}{c}10.12 \\
(0.018)\end{array}$ & . & $\begin{array}{l}10.18 \\
(0.017)\end{array}$ & . \\
\hline \multirow[t]{4}{*}{ Observations } & \multicolumn{2}{|r|}{981} & \multicolumn{2}{|c|}{1077} & \multicolumn{2}{|c|}{1034} \\
\hline & \multicolumn{6}{|c|}{ Girls } \\
\hline & \multicolumn{2}{|c|}{ Wave 1 (age 14) } & \multicolumn{2}{|c|}{ Wave 2 (age 15 ) } & \multicolumn{2}{|c|}{ Wave 3 (age 16 ) } \\
\hline & $\begin{array}{l}\text { Transfer } \\
\text { (1st stg) }\end{array}$ & $\begin{array}{l}\text { Work Hours } \\
\text { (2nd stg) }\end{array}$ & $\begin{array}{l}\text { Transfer } \\
\text { (1st stg) }\end{array}$ & $\begin{array}{l}\text { Work Hours } \\
\text { (2nd stg) }\end{array}$ & $\begin{array}{l}\text { Transfer } \\
\text { (1st stg) }\end{array}$ & $\begin{array}{l}\text { Work Hours } \\
\text { (2nd stg) }\end{array}$ \\
\hline Work Hours & . & $\begin{array}{c}0.018 \\
(0.021)\end{array}$ & . & $\begin{array}{c}0.006 \\
(0.167)\end{array}$ & . & $\begin{array}{l}-0.029^{* * *} \\
(0.009)\end{array}$ \\
\hline $\begin{array}{l}\text { 'Permanant' income } \\
\text { percentile }\end{array}$ & $\begin{array}{c}4.624 \\
(2.522)\end{array}$ & $\begin{array}{c}0.044 \\
(0.021)\end{array}$ & $\begin{array}{l}1.616 \\
(2.833)\end{array}$ & $\begin{array}{c}0.125 \\
(0.104)\end{array}$ & $\begin{array}{l}6.094^{*} \\
(3.123)\end{array}$ & $\begin{array}{l}-0.046 \\
(0.113)\end{array}$ \\
\hline IMD (standardized) & $\begin{array}{c}0.217 \\
(0.734)\end{array}$ & . & $\begin{array}{l}-0.278 \\
(0.942)\end{array}$ & . & $\begin{array}{c}-1.596^{*} \\
(0.906)\end{array}$ & . \\
\hline Birth month & $\begin{array}{c}-0.331^{*} \\
(0.184)\end{array}$ & . & $\begin{array}{l}-0.116 \\
(0.195)\end{array}$ & . & $\begin{array}{c}-0.569^{* *} \\
(0.259)\end{array}$ & . \\
\hline $\begin{array}{l}\text { LAD age } 16-64 \\
\text { unemployment rate }\end{array}$ & $\begin{array}{l}-0.085 \\
(0.732)\end{array}$ & . & $\begin{array}{l}-0.586 \\
(0.853)\end{array}$ & . & $\begin{array}{l}-0.875 \\
(0.707)\end{array}$ & . \\
\hline $\begin{array}{l}\text { Joint significance of labour } \\
\text { market variables: } \chi_{3}^{2}(p \text {-value })\end{array}$ & $\begin{array}{c}3.28 \\
(0.350)\end{array}$ & . & $\begin{array}{c}1.09 \\
(0.780)\end{array}$ & . & $\begin{array}{l}13.86 \\
(0.003)\end{array}$ & . \\
\hline Observations & & 485 & & 482 & & 447 \\
\hline
\end{tabular}

Notes: Joint significance statistics and p-values are Wald test statistics. Coefficients in transfer column presented as average marginal effects on the probability of a positive transfer being made. Standard errors, clustered by school, in parentheses. Longitudinal weights applied. *: on the probability of a positive transfer being made. Standard errors, clustered by school, in parentheses. Longitudinal weights applied. *: $p \leq 0.1 ; *: p \leq 0.05 ; * *: p \leq 0.01$. Index of multiple deprivation is standardized by substracting the mean and dividing by standard deviation.
Month-of-birth within academic year: Sept (oldest in year) $=1$, Aug (youngest in year) $=12$. Prior educational performance is standardized average point score at age 11 (Key Stage 2) in wave 1, and age 14 (Key Stage 3) in waves 2 and 3. Additional controls: Parent's highest average point score at age 11 (Key Stage 2) in wave 1, and age 14 (Key Stage 3) in waves 2 and 3. Additional controls: Parent's highest
qualification, Parent's socio-economic status, parents' employment, child's prior educational performance, resident and non-resident siblings, lone parent family, child's special educational needs (SEN) classification, urban-rural classification, child's ethnicity, timing of interview. 
Table A4: Estimation results for subpopulation of parents who have no qualifications: Childleading model

\section{Subpopulation: Parent has no qualifications}

\section{Boys}

\begin{tabular}{|c|c|c|c|c|c|c|}
\hline & \multicolumn{2}{|c|}{ Wave 1 (age 14 ) } & \multicolumn{2}{|c|}{ Wave 2 (age 15$)$} & \multicolumn{2}{|c|}{ Wave 3 (age 16) } \\
\hline & $\begin{array}{l}\text { Transfer } \\
\text { (1st stg) }\end{array}$ & $\begin{array}{l}\text { Work Hours } \\
\text { (2nd stg) }\end{array}$ & $\begin{array}{l}\text { Transfer } \\
(1 \mathrm{st} \text { stg) }\end{array}$ & $\begin{array}{l}\text { Work Hours } \\
\text { (2nd stg) }\end{array}$ & $\begin{array}{l}\text { Transfer } \\
\text { (1st stg) }\end{array}$ & $\begin{array}{l}\text { Work Hours } \\
\text { (2nd stg) }\end{array}$ \\
\hline Work Hours & . & $\begin{array}{l}-0.021 \\
(0.173)\end{array}$ & . & $\begin{array}{l}-0.021^{*} \\
(0.013)\end{array}$ & . & $\begin{array}{l}-0.017 \\
(0.013)\end{array}$ \\
\hline $\begin{array}{l}\text { 'Permanant' income } \\
\text { percentile }\end{array}$ & $\begin{array}{l}5.523^{* *} \\
(2.763)\end{array}$ & $\begin{array}{c}0.062 \\
(0.100)\end{array}$ & $\begin{array}{l}4.234 \\
(5.181)\end{array}$ & $\begin{array}{c}0.053 \\
(0.109)\end{array}$ & $\begin{array}{l}2.526 \\
(5.347)\end{array}$ & $\begin{array}{l}0.062 \\
(0.114)\end{array}$ \\
\hline IMD (standardized) & $\begin{array}{c}-1.901 * * * \\
(0.526)\end{array}$ & . & $\begin{array}{l}-0.116 \\
(1.114)\end{array}$ & . & $\begin{array}{l}-1.048 \\
(1.187)\end{array}$ & \\
\hline Birth month & $\begin{array}{l}-0.082 \\
(0.145)\end{array}$ & . & $\begin{array}{l}-0.139 \\
(0.314)\end{array}$ & . & $\begin{array}{l}-0.556 \\
(0.417)\end{array}$ & . \\
\hline $\begin{array}{l}\text { LAD age 16-64 } \\
\text { unemployment rate }\end{array}$ & $\begin{array}{c}0.366 \\
(0.534)\end{array}$ & . & $\begin{array}{l}-0.950 \\
(1.013)\end{array}$ & . & $\begin{array}{l}0.432 \\
(0.826)\end{array}$ & \\
\hline $\begin{array}{l}\text { Joint significance of labour } \\
\text { market variables: } \chi_{3}^{2}(p \text {-value })\end{array}$ & $\begin{array}{l}14.08 \\
(0.003)\end{array}$ & . & $\begin{array}{l}1.69 \\
(0.639)\end{array}$ & & $\begin{array}{c}4.85 \\
(0.183)\end{array}$ & \\
\hline Observations & & 806 & & 727 & & 731 \\
\hline
\end{tabular}

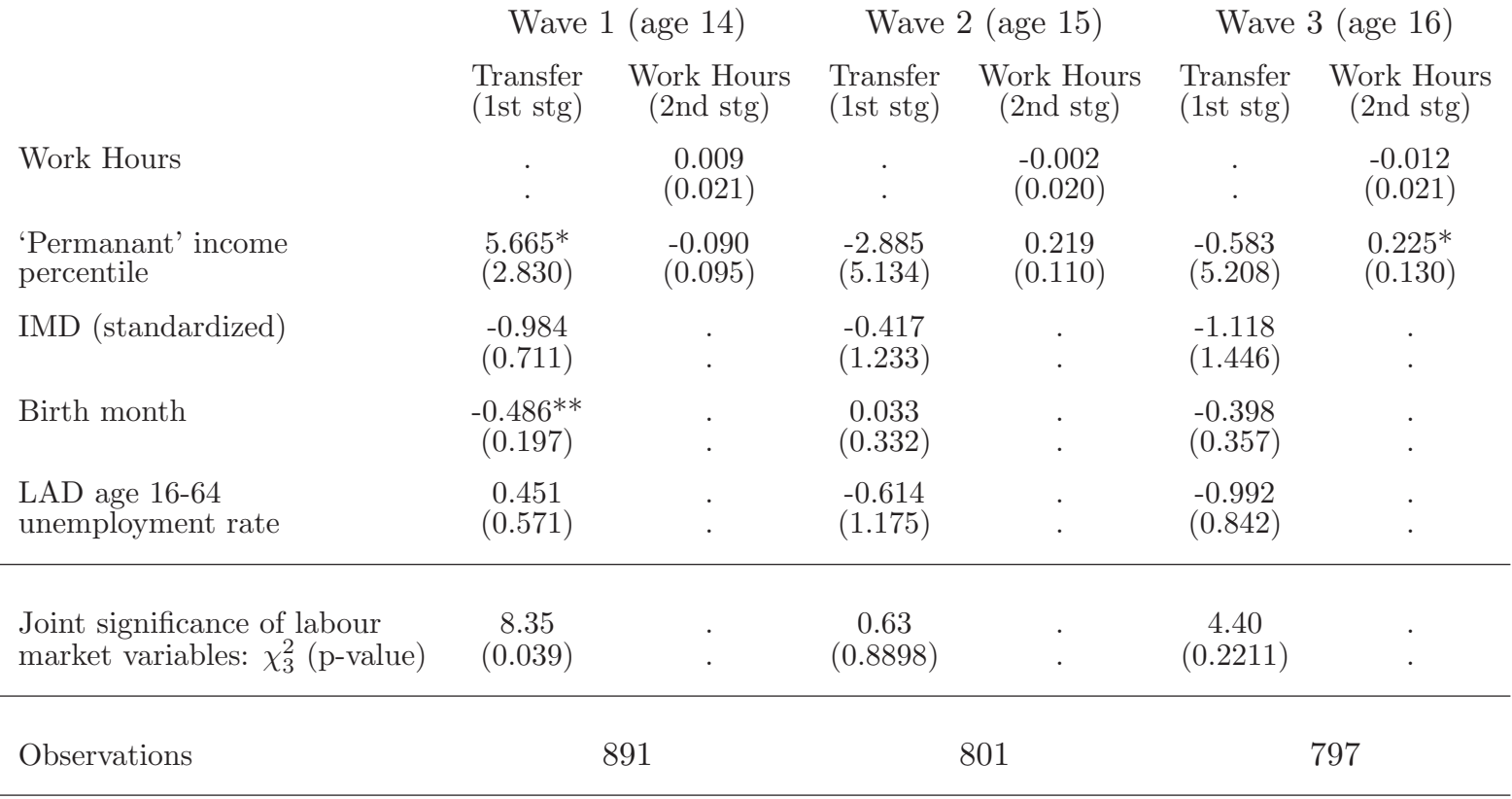

Notes: Joint significance statistics and p-values are Wald test statistics. Coefficients in transfer column presented as average marginal effects on the probability of a positive transfer being made. Standard errors, clustered by school, in parentheses. Longitudinal weights applied. *: $p \leq 0.1 ; * *: p \leq 0.05 ; * * *: p \leq 0.01$. Index of multiple deprivation is standardized by substracting the mean and dividing by standard deviation. Month-of-birth within academic year: Sept (oldest in year) $=1$, Aug (youngest in year) $=12$. Prior educational performance is standardized (11 (Key Stage 2) in average qualification, Parent's socio-economic status, parents' employment, child's prior educational performance, resident and non-resident siblings, 


\section{A.3 Observed social interactions}

This section derives the child's labour supply response to unearned income in the Nash or parent-leading Stackelberg models and the parent's transfer response to child labour supply in the Nash or child-leading Stackelberg model. These parameters are derived from the implicit functions which are the first-order conditions in equations (4) and (9).

\section{A.3.1 The labour supply response to unearned income}

The child's first-order condition is:

$$
[.]=w \cdot U_{C}^{c}+H_{L} \cdot U_{H}^{c}=0
$$

Using implicit differentiation, the parameter of interest is equal to:

$$
\begin{gathered}
\frac{\partial L}{\partial t}=-\frac{\left[\frac{\partial[\cdot]}{\partial t}\right]}{\left[\frac{\partial \cdot \cdot]}{\partial L}\right]} \\
=-\frac{\frac{\partial\left[w U_{C}^{c}\right]}{\partial t}+\frac{\partial\left[U_{H}^{c} H_{L}\right]}{\left.\partial U_{C}^{c}\right]}}{\frac{\left.\partial U_{C}^{c}\right]}{\partial L}+\frac{\partial\left[U_{H}^{H} H_{L}\right]}{\partial L}}
\end{gathered}
$$

The elements of this expression are as follows:

- $\quad \frac{\partial\left[w \cdot U_{C}^{c}\right]}{\partial t}=w U_{C C}^{c}: w$ is constant, and increasing t by 1 increases consumption by 1 .

- $\frac{\partial\left[U_{H}^{c} H_{L}\right]}{\partial t}=0$ : Human capital production function is invariant to transfers, and marginal utility from human capital and consumption are separable.

- $\quad \frac{\partial\left[w U_{C}^{c}\right]}{\partial L}=w^{2} U_{C C}^{c}: w$ is constant, and increasing L by 1 changes marginal utility of consumption as though consumption increased by $w$.

- $\frac{\partial\left[U_{H}^{c} H_{L}\right]}{\partial L}=U_{H H}^{c}\left(H_{L}\right)^{2}+U_{H}^{c} \cdot H_{L L}$ : Using the product rule, bearing in mind that $U_{H}^{c}$ is itself a function of $H$.

Multiplying and dividing the whole expression by $w$, the parameter of interest is:

$$
\frac{\partial L}{\partial t}=-\frac{1}{w} \cdot \frac{w^{2} \cdot U_{C C}^{c}}{w^{2} \cdot U_{C C}^{c}+\left(H_{L}\right)^{2} \cdot U_{H H}^{c}+U_{H}^{c} H_{L L}}
$$


This means that $-\frac{1}{w}<\frac{\partial L}{\partial t}<0$. The child always withdraws labour earnings at a slower rate than transfers are received. Hence, in the Nash or parent-leading Stackelberg model, child's consumption is strictly increasing in cash transfers.

\section{A.3.2 The 'tax' rate}

The parent's first-order condition is:

$$
[\cdot]=-U_{P}^{p}+U_{C}^{p}=0
$$

The parameter of interest is therefore equal to:

$$
\begin{gathered}
\frac{\partial t}{\partial L}=-\frac{\left[\frac{\partial[\cdot]}{\partial L}\right]}{\left[\frac{\partial[\cdot]}{\partial t}\right]} \\
=-\frac{-\frac{\partial U_{P}^{p}}{\partial L}+\frac{\partial U_{C}^{p}}{\partial L}}{-\frac{\partial U_{P}^{p}}{\partial t}+\frac{\partial U_{C}^{p}}{\partial t}}
\end{gathered}
$$

The elements of this expression are as follows:

- $\quad \frac{\partial U_{P}^{p}}{\partial L}=0$ : Child's labour supply has no effect on parent's consumption.

- $\frac{\partial U_{C}^{p}}{\partial L}=w \cdot U_{C C}^{p}$ : Increasing consumption by 1 means $U_{C}^{p}$ changes by $U_{C C}^{p}$, so at the margin, increasing consumption by $w$ means $U_{C}^{p}$ changes by $w \cdot U_{C C}^{p}$.

- $\frac{\partial U_{P}^{p}}{\partial t}=-U_{P P}^{p}$ : Increasing $t$ by 1 has same effect as reducing own consumption by 1 .

- $\quad \frac{\partial U_{C}^{p}}{\partial t}=U_{C C}^{p}$ : Increasing $t$ by 1 has same effect as increasing child's consumption by 1 .

This means the parameter of interest is:

$$
\frac{\partial t}{\partial L}=-w \cdot \frac{U_{C C}^{p}}{U_{P P}^{p}+U_{C C}^{p}}
$$

This can be expressed as the 'tax' rate, in response to earnings rather than labour supply:

$$
\frac{\partial t}{\partial L} \cdot \frac{1}{w}=-\frac{U_{C C}^{p}}{U_{P P}^{p}+U_{C C}^{p}}
$$

The denominator here is more negative than numerator, so the expression is strictly between zero and minus 1: the 'tax rate' is strictly between 0 and $100 \%$. This means that in the Nash 
or child-leading Stackelberg model, the parent withdraws transfers at a rate slower than wages are earned, so the child's consumption is strictly increasing in his labour supply. 


\section{A.4 Differentiated labour markets by gender}

\section{A.4.1 Job types}

The LSYPE does not provide information on the types of jobs teenagers do. Howieson et al. (2006) indicate the extent to which boys' and girls' labour markets are differentiated in Scotland, where the education system, labour market conditions and legislation are very similar to England. The largest categories of employment among those aged 14 and under are newspaper delivery (32\% of workers, among which boys outnumber girls by a factor of five) and babysitting (11\% of workers, among which girls outnumber boys by a factor of six). In both cases, the gender bias is partly driven by differences in physical and mental attributes affecting individuals' ability to do the job well, but also by social norms for gender roles. This suggests that the size and male dominance of the market for newspaper delivery is responsible for the higher male employment at age 13-14, when few other jobs are available.

The largest categories of employment among 15 and 16 year olds are "cafés and restaurants" (17.5\%), "other shops" (14\%) and "chain stores" (12\%), with females more heavily concentrated in these industries than males. Jobs in these categories are also likely to be restricted to 16 yearolds in law (due to health and safety requirements in food preparation or the sale of alcohol) or 15 year-olds in practice (because this enables an eight hour shift to be supplied on a Saturday).

\section{A.4.2 Gender roles and ethnicity}

Table A5 shows that the overall trends in employment are driven by the majority white ethnic group, who also have the highest employment levels for both sexes at every wave. There is considerable variation in employment rates and trajectories among the other ethnic groups. This will reflect a combination of socio-cultural norms, prior educational performance, poorer labour market opportunities and active labour market discrimination, but also rigid gender roles within certain ethnic groups which make employment among girls exceptionally rare. In particular, Pakistani and Bangladeshi girls are almost completely excluded from the labour market. This makes it sensible to estimate our models separately for boys and girls. ${ }^{19}$

\footnotetext{
${ }^{19}$ In both the parent-leading and child-leading specifications several ethnicity dummies are statistically significant in both transfer and labour supply equations. Ethnicity therefore makes a difference in levels. However, by re-estimating on white students only and obtaining very similar results, we find no evidence for significant ethnicity interactions with the parameters of interest.
} 
Table A5: Employment rates by wave, sex and ethnicity

\begin{tabular}{lccccccccc}
\hline \hline & \multicolumn{3}{c}{ Wave 1 } & \multicolumn{3}{c}{ Wave 2} & \multicolumn{4}{c}{ Wave 3 } \\
& Boys & Girls & & Boys & Girls & Boys & Girls & \\
White & $25.7 \%$ & $21.3 \%$ & $* * *$ & $31.4 \%$ & $30.3 \%$ & $30.8 \%$ & $34.8 \%$ & $\# \# \#$ \\
Mixed & $15.7 \%$ & $16.0 \%$ & & $15.6 \%$ & $19.9 \%$ & & $24.5 \%$ & $20.5 \%$ & \\
Indian & $9.4 \%$ & $4.4 \%$ & $* * *$ & $12.1 \%$ & $5.0 \%$ & $* * *$ & $10.1 \%$ & $3.4 \%$ & $* * *$ \\
Pakistani & $7.0 \%$ & $<1.5 \%$ & $* * *$ & $6.4 \%$ & $<1.5 \%$ & $* * *$ & $8.0 \%$ & $<1.5 \%$ & $* * *$ \\
Bangladeshi & $4.5 \%$ & $<1.5 \%$ & $* * *$ & $5.8 \%$ & $<1.5 \%$ & $* * *$ & $7.2 \%$ & $3.1 \%$ & $*$ \\
Black Caribbean & $11.2 \%$ & $9.6 \%$ & & $11.5 \%$ & $10.7 \%$ & & $12.1 \%$ & $14.7 \%$ & \\
Black African & $7.8 \%$ & $4.7 \%$ & & $10.1 \%$ & $5.2 \%$ & & $6.0 \%$ & $8.7 \%$ & \\
Other & $15.3 \%$ & $9.8 \%$ & & $16.7 \%$ & $8.1 \%$ & & $12.8 \%$ & $11.1 \%$ & \\
\hline \hline
\end{tabular}

Symbols: *, **, ***: Boys' employment higher than girls' at $5 \%, 1 \%$ and $0.1 \%$ levels respectively. \#, \#\#, \#\#\#: Girls' employment higher than boys' at $5 \%, 1 \%$ and $0.1 \%$ levels respectively. Standard errors clustered by school. Population proportions calculated using final probability weights. 


\section{A.5 Distinguishing household and market work}

We do not observe job types but have assumed that the question on labour supply is interpreted as referring to market work. We assume that this includes informal employment in the parent's own business, and that survey respondents distinguish the payments they receive for this work from pocket money or allowances. However, it is possible that teenagers may regard babysitting within as well as outside the household as 'paid work', yet double-count the payment they receive as part of their reported transfers. If this is true the observed labour supply response (parentleading model) or parent's 'tax rate' (child-leading model) will be positively biased (less negative or more positive than the true effect).

We test this hypothesis by re-estimating the model for children with no younger siblings, for whom there is no possibility of babysitting within the household. The key results are shown in table A6. The coefficient on receiving cash transfers for girls in wave 1 of the parentleading model becomes less positive and insignificantly different from zero. The coefficient for boys has become more negative (though the change is less drastic) and is now statistically significant. These results lend qualified support to our initial rejection of the parent-leading Stackelberg model based on 13-14 year-old girls' apparent positive labour supply response to parental transfers being due to this babysitting hypothesis. However, the parent's significant positive transfer response to both the IMD and month of birth means these results are still inconsistent with the parent-leading Stackelberg model.

In the child-leading model, the wave 1 labour supply of daughters with no younger siblings appears to be associated with a small 'subsidy', or increase in probability of transfers. This finding at face value rejects the babysitting hypothesis, but this coefficient is very imprecisely estimated and not statistically different from zero or the pooled-sample coefficient. The coefficients on cash transfers or labour supply do not change significantly either for boys or for older girls (for whom we assume this matters less - see discussion in Appendix A.4, above), though the conclusion drawn would change: statistically significant 'tax rates' are now observed in wave 2 rather than wave 3 . It is possible that as children with 'no younger siblings' are more likely to have 'some older siblings' than the pooled sample, this reflects parents having a softer attitude towards labour supply in the final year of school, once they have seen how older siblings coped. 
Table A6: Estimation results for sample members with no younger siblings.

\begin{tabular}{|c|c|c|c|c|c|c|c|c|}
\hline & \multicolumn{8}{|c|}{ Boys } \\
\hline & \multicolumn{2}{|c|}{ Parent-leading } & \multicolumn{6}{|c|}{ Child-leading } \\
\hline & \multicolumn{2}{|c|}{ Wave 1} & \multicolumn{2}{|c|}{ Wave 1} & \multicolumn{2}{|c|}{ Wave 2} & \multicolumn{2}{|c|}{ Wave 3} \\
\hline & $\begin{array}{l}\text { Transfer } \\
\text { (FIML 1st) }\end{array}$ & $\begin{array}{l}\text { Work Hours } \\
\text { (FIML 2nd) }\end{array}$ & $\begin{array}{l}\text { Work Hours } \\
\text { (FIML 1st) }\end{array}$ & $\begin{array}{l}\text { Transfer } \\
\text { (FIML 2nd) }\end{array}$ & $\begin{array}{l}\text { Work Hours } \\
\text { (FIML 1st) }\end{array}$ & $\begin{array}{l}\text { Transfer } \\
\text { (FIML 2nd) }\end{array}$ & $\begin{array}{l}\text { Work Hours } \\
\text { (FIML 1st) }\end{array}$ & $\begin{array}{l}\text { Transfer } \\
\text { (FIML 2nd) }\end{array}$ \\
\hline Transfer & & $\begin{array}{l}-3.072^{*} \\
(1.787)\end{array}$ & . & & & . & & \\
\hline Work Hours & . & . & . & $\begin{array}{l}-0.009 \\
(0.008)\end{array}$ & . & $\begin{array}{l}-0.013^{*} \\
(0.007)\end{array}$ & . & $\begin{array}{l}-0.003 \\
(0.007)\end{array}$ \\
\hline $\begin{array}{l}\text { 'Permanent' income } \\
\text { percentile }\end{array}$ & $\begin{array}{l}0.121^{* *} \\
(0.059)\end{array}$ & . & $\begin{array}{l}-1.244 \\
(1.494)\end{array}$ & $\begin{array}{l}0.095^{*} \\
(0.056)\end{array}$ & $\begin{array}{l}-1.231 \\
(1.760)\end{array}$ & $\begin{array}{l}0.118^{* *} \\
(0.059)\end{array}$ & $\begin{array}{c}3.412 \\
(2.072)\end{array}$ & $\begin{array}{l}-0.081 \\
(0.065)\end{array}$ \\
\hline IMD (standardized) & $\begin{array}{c}0.009 \\
(0.016)\end{array}$ & $\begin{array}{c}-0.942^{* * * *} \\
(0.367)\end{array}$ & $\begin{array}{c}-0.994^{* * * *} \\
(0.342)\end{array}$ & & $\begin{array}{l}-0.688^{*} \\
(0.394)\end{array}$ & & $\begin{array}{l}-0.936^{*} \\
(0.539)\end{array}$ & \\
\hline Birth month & $\begin{array}{l}-0.004 \\
(0.004)\end{array}$ & $\begin{array}{l}-0.113 \\
(0.085)\end{array}$ & $\begin{array}{l}-0.104 \\
(0.088)\end{array}$ & . & $\begin{array}{c}-0.104^{*} \\
(0.096)\end{array}$ & . & $\begin{array}{c}-0.233^{*} \\
(0.147)\end{array}$ & . \\
\hline $\begin{array}{l}\text { LEA age 16-64 } \\
\text { unemployment rate }\end{array}$ & $\begin{array}{l}0.016 \\
(0.012)\end{array}$ & $\begin{array}{l}0.028 \\
(0.271)\end{array}$ & $\begin{array}{l}-0.004 \\
(0.275)\end{array}$ & . & $\begin{array}{l}-0.583^{*} \\
(0.312)\end{array}$ & . & $\begin{array}{c}-0.678^{*} \\
(0.373)\end{array}$ & . \\
\hline $\begin{array}{l}\text { Joint significance of labour } \\
\text { market variables: } \chi_{3}^{2} \\
\text { (p-value) }\end{array}$ & . & $\begin{array}{l}11.88 \\
(0.008)\end{array}$ & $\begin{array}{l}13.03 \\
(0.005)\end{array}$ & . & $\begin{array}{l}11.59 \\
(0.009)\end{array}$ & . & $\begin{array}{l}11.98 \\
(0.008)\end{array}$ & . \\
\hline \multirow[t]{5}{*}{ Observations } & \multicolumn{2}{|c|}{1881} & \multicolumn{2}{|c|}{1881} & \multicolumn{2}{|c|}{1881} & \multicolumn{2}{|c|}{1881} \\
\hline & \multicolumn{8}{|c|}{ Girls } \\
\hline & \multicolumn{2}{|c|}{ Parent-leading } & \multicolumn{6}{|c|}{ Child-leading } \\
\hline & \multicolumn{2}{|c|}{ Wave 1} & \multicolumn{2}{|c|}{ Wave 1} & \multicolumn{2}{|c|}{ Wave 2} & \multicolumn{2}{|c|}{ Wave 3} \\
\hline & $\begin{array}{l}\text { Transfer } \\
\text { (FIML 1st) }\end{array}$ & $\begin{array}{l}\text { Work Hours } \\
\text { (FIML 2nd) }\end{array}$ & $\begin{array}{l}\text { Work Hours } \\
\text { (FIML 1st) }\end{array}$ & $\begin{array}{l}\text { Transfer } \\
\text { (FIML 2nd) }\end{array}$ & $\begin{array}{l}\text { Work Hours } \\
\text { (FIML 1st) }\end{array}$ & $\begin{array}{l}\text { Transfer } \\
\text { (FIML 2nd) }\end{array}$ & $\begin{array}{l}\text { Work Hours } \\
\text { (FIML 1st) }\end{array}$ & $\begin{array}{l}\text { Transfer } \\
\text { (FIML 2nd) }\end{array}$ \\
\hline Transfer & . & $\begin{array}{c}2.592 \\
(3.714)\end{array}$ & & & & & & \\
\hline Work Hours & . & . & . & $\begin{array}{l}0.010 \\
(0.010)\end{array}$ & . & $\begin{array}{c}-0.018^{*} \\
(0.009)\end{array}$ & . & $\begin{array}{l}-0.009 \\
(0.007)\end{array}$ \\
\hline $\begin{array}{l}\text { 'Permanent' income } \\
\text { percentile }\end{array}$ & $\begin{array}{l}0.088^{*} \\
(0.052)\end{array}$ & . & $\begin{array}{l}1.004 \\
(1.435)\end{array}$ & $\begin{array}{c}0.066 \\
(0.054)\end{array}$ & $\begin{array}{l}-1.478 \\
(1.502)\end{array}$ & $\begin{array}{l}0.117^{* *} \\
(0.009)\end{array}$ & $\begin{array}{l}-1.168 \\
(1.680)\end{array}$ & $\begin{array}{c}0.083 \\
(0.057)\end{array}$ \\
\hline IMD (standardized) & $\begin{array}{l}0.028^{* *} \\
(0.014)\end{array}$ & $\begin{array}{c}-0.907^{* *} \\
(0.444)\end{array}$ & $\begin{array}{l}-0.697^{*} \\
(0.395)\end{array}$ & & $\begin{array}{l}-0.240 \\
(0.395)\end{array}$ & & $\begin{array}{l}-1.107^{*} \\
(0.490)\end{array}$ & \\
\hline Birth month & $\begin{array}{l}0.007^{*} \\
(0.004)\end{array}$ & $\begin{array}{c}-0.279 * * * \\
(0.093)\end{array}$ & $\begin{array}{c}-0.223^{* * *} \\
(0.086)\end{array}$ & . & $\begin{array}{l}-0.098 \\
(0.080)\end{array}$ & . & $\begin{array}{c}-0.386^{* *} \\
(0.123)\end{array}$ & : \\
\hline $\begin{array}{l}\text { LEA age } 16-64 \\
\text { unemployment rate }\end{array}$ & $\begin{array}{l}-0.006 \\
(0.010)\end{array}$ & $\begin{array}{l}-0.558^{*} \\
(0.312)\end{array}$ & $\begin{array}{c}-0.596 * * \\
(0.295)\end{array}$ & . & $\begin{array}{c}-1.074^{* * *} \\
(0.329)\end{array}$ & . & $\begin{array}{c}-1.092^{* * * *} \\
(0.317)\end{array}$ & . \\
\hline $\begin{array}{l}\text { Joint significance of labour } \\
\text { market variables: } \chi_{3}^{2} \\
\text { (p-value) }\end{array}$ & & $\begin{array}{c}23.17 \\
(0.000)\end{array}$ & $\begin{array}{c}22.38 \\
(0.000)\end{array}$ & . & $\begin{array}{c}16.35 \\
(0.001)\end{array}$ & . & $\begin{array}{c}28.09 \\
(0.000)\end{array}$ & . \\
\hline Observations & 19 & 15 & 19 & & 19 & & 19 & 16 \\
\hline
\end{tabular}

Notes: Joint significance statistics and p-values are Wald test statistics. Coefficients in transfer column presented as average marginal effects on the probability of a positive transfer being made presented in accompanying graphs). Standard errors, clustered by school, in parentheses. Longitudinal weights applied. $*: p<0.1 ; * *: p<0.05 ; * * *: p<0.01$. Index of multiple deprivation is standardized by substracting the mean and dividing by standard deviation. Month-of-birth within academic year: Sept (oldest in year) $=1$, Aug (youngest in year) $=$ 12. Prior educational performance is Additional controls: Parent's socio-economic status, parents' employment, child's prior educational performance (standardized average point score at age 11 - Key Stage 2 - in wave 1 and age 14 - Key Stage 3 - in waves 2 and 3), resident and non-resident siblings, lone parent family, step family, parent's ill health limits activities, household own's home (morgage or outright), child's special educational needs (SEN) classification, urban-rural classification, child's ethnicity, timing of interview. 


\section{A.6 Complete estimation output}

The complete maximum likelihood estimation output for the parent-leading Stackelberg model is shown in Tables A7-A8, and the child-leading Stackelberg model in Tables A9-A10, starting overleaf. Tables 4-7 in the main body presented average marginal effects on the probability of transfer for a set of key variables. Here we show the probit linear latent regression coefficients for both dependent and all explanatory variables. We omit the output for the baseline specifications assuming that transfers and labour supply are exogenous in the second stage of the parentleading and child-leading specifications respectively. 


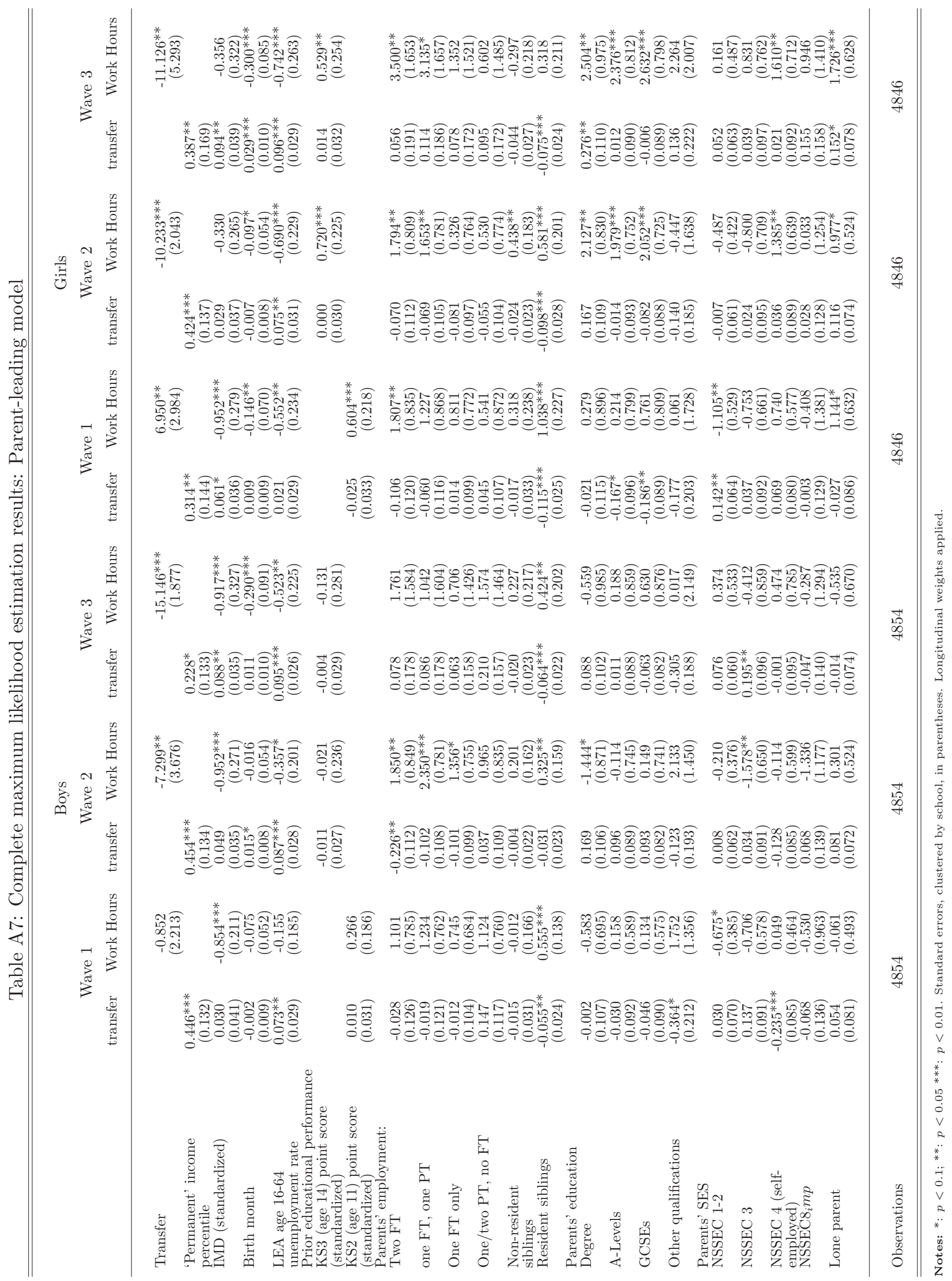




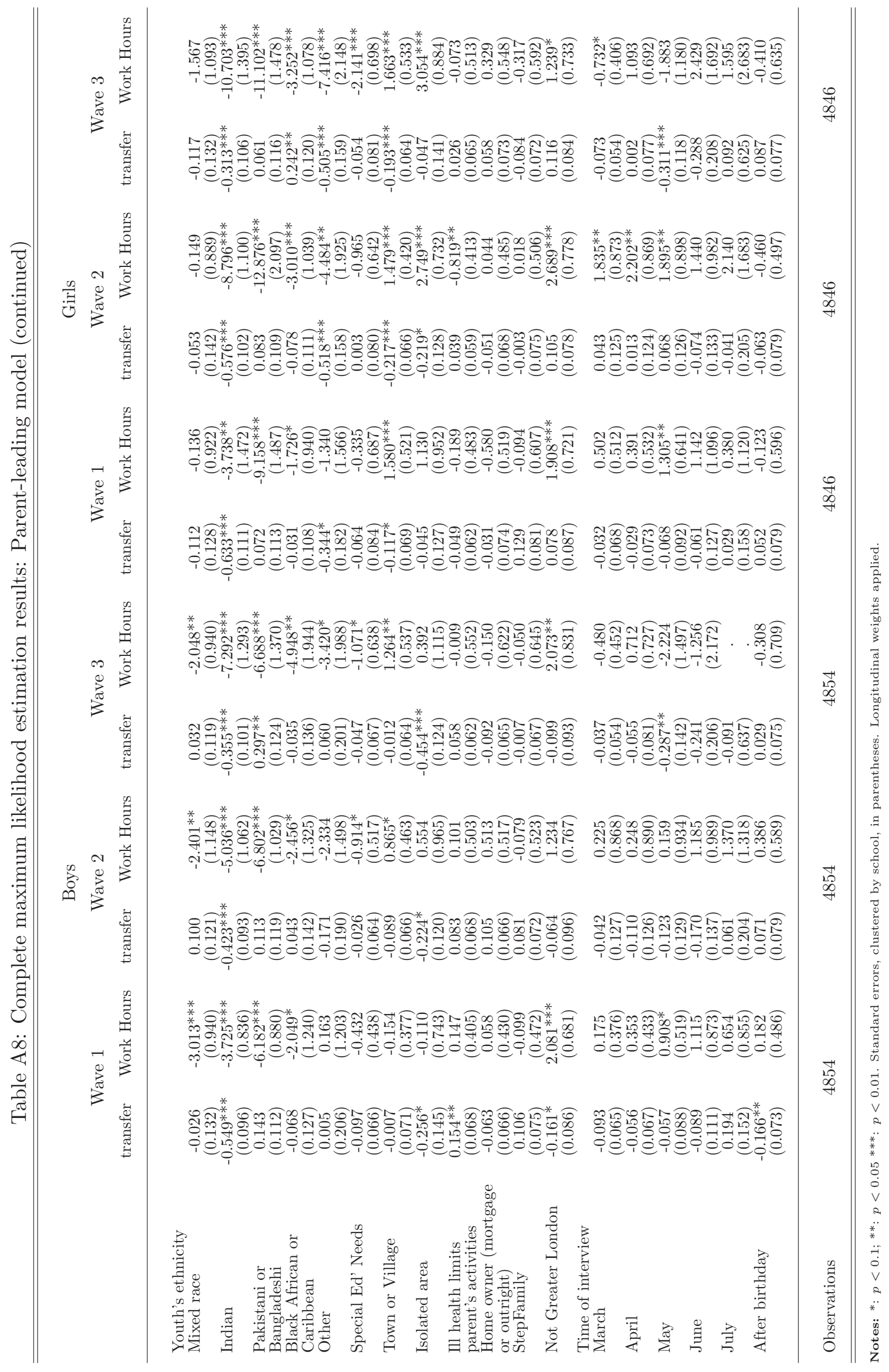




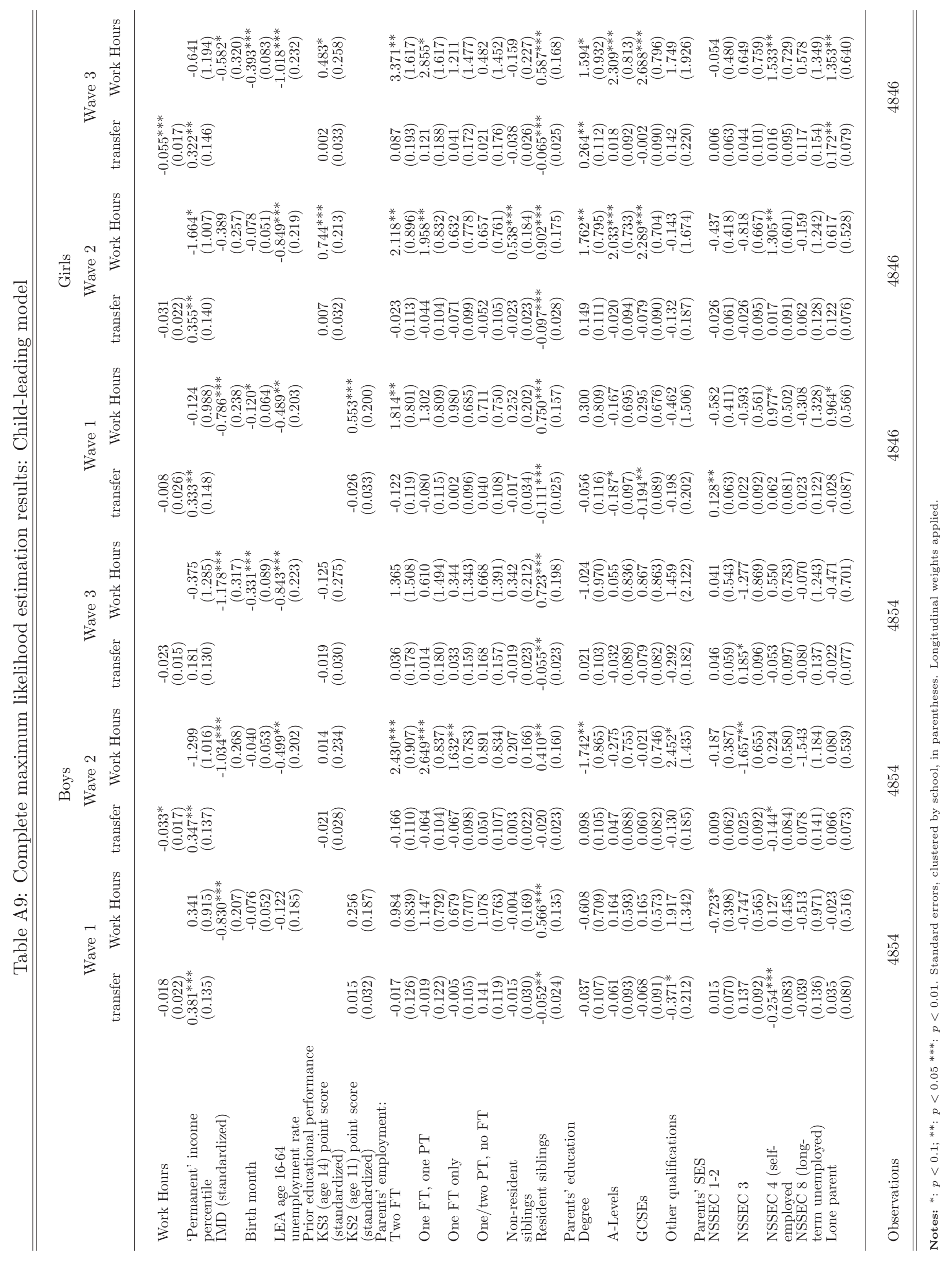




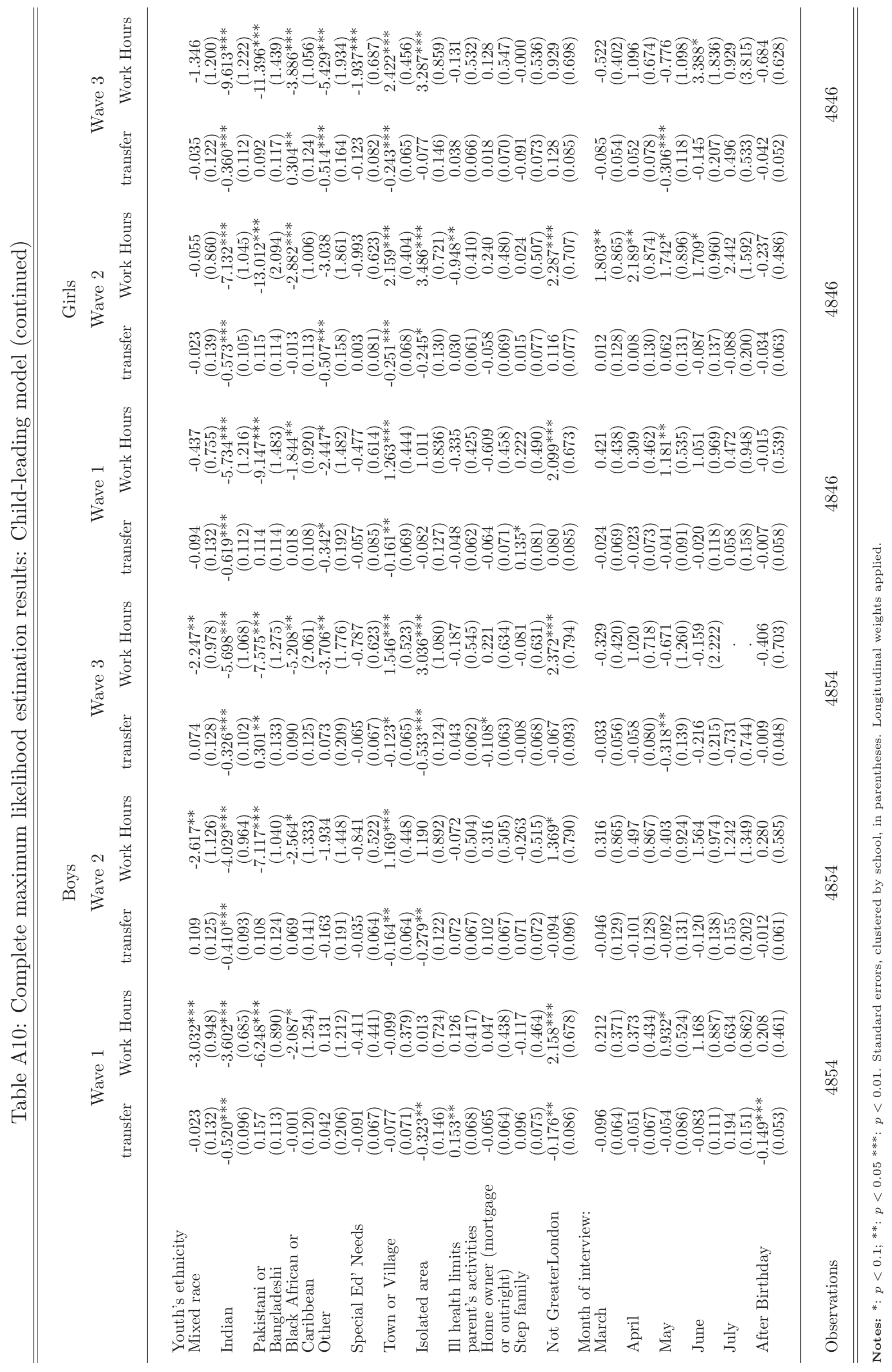

